\title{
CONCENTRATION OF UKRAINE'S BANKING SYSTEM: MYTHS AND FACTS
}

Vladyslav Rashkovan

National Bank of Ukraine
Roman Kornyliuk

Vadym Hetman Kyiv National

Economic University

\begin{abstract}
This article attempts to find answers to questions of current significance: How concentrated is Ukraine's banking system from the viewpoint of the world's best regulatory practices and in comparison with other countries? What has been the driving force behind the growing concentration in recent years and does this process pose a threat to competition in the banking system? What effect would mergers and acquisitions in the banking sector have on the concentration of the banking system? And finally, do public authorities have to stimulate consolidation in the banking system or, on the contrary, restrain potential bank mergers and acquisitions?
\end{abstract}

The results of empirical analysis dispel the persisting myths about the risks of fast and excessive concentration resulting from continuing market consolidation and about the substantial impact of inequality on the growing concentration, and refute the perceived danger of mergers and acquisitions in the banking sector. Instead, it was discovered that concentration of banking assets in Ukraine is not substantial according to the Herfindahl-Hirschman Index (HHI), CRn concentration index and other ratios. At the same time, in the conditions of continuing consolidation of the banking system via mergers and acquisitions and a decreasing number of banks, upward trends are observed within moderate, average European levels. Therefore, these new conditions require closer attention on the part of banking regulators to assess possible consequences of concentration.

This article provides recommendations to the National Bank of Ukraine (NBU) and the Antimonopoly Committee of Ukraine (AMCU) on how to improve monitoring of banking concentration processes and better regulate consolidation processes in bank mergers and acquisitions. A complex of preventive macroprudential measures was offered to offset the negative consequences of concentration and achieve an optimal degree of market consolidation.

JEL Codes: G18, G21, G28, L1, L4

Keywords: banking system, concentration, consolidation, macroprudential regulation, systemic risk.

\section{Introduction}

During the past two years, Ukraine's banking system has been undergoing active structural transformation: the number of banks has been declining and requirements for transparency of banking transactions and bank equity were becoming more stringent. The decline in the number of market participants and the growing inequality among them lead to an increasing concentration which, on one hand, is boosting the banking market's capacity and effectiveness, but, on the other hand, may facilitate formation of an oligopoly or monopoly on a regional or product market with numerous adverse external effects or the appearance of problematic "too big to fail" banks. In other words, concentration simultaneously generates positive consequences for the banking system and bank customers while posing a threat to competition. 
Therefore, concentration is gradually turning from a subject for scholarly discussions to a case study for the Ukrainian financial regulator. The increasing attention on part of the NBU to the assessment of concentration is manifested by the inclusion in the $\mathrm{HHI}$ of at least 800 points in terms of assets to the list of key fulfillment indicators for the Comprehensive Program of Ukraine Financial Sector Development until 2020 (NBU, 2015). Since the target minimum concentration level was achieved in 3Q 2015, it might be necessary to set additional parameters for a maximum concentration level in order to prevent its longterm negative consequences.

Simultaneously with increasing concentration, Ukraine's banking market experiences the following process: consolidation of the banking system that manifests itself in a decreasing number and growing size of banks, partially boosted by the increasing regulatory and market requirements for the minimum amount and adequacy of capital. Depending on the individual stress resistance of banks and decisions by the top management of financial institutions and the banking regulator, consolidation processes may take the form of removal of insolvent financial institutions from the market, intensifying mergers and acquisitions, and uneven natural growth of assets among banks. Some of the aforementioned processes, e.g., the declining number of banks due to failure to comply with the NBU's norms, have been actively taking place in Ukraine since the beginning of 2014, while mergers and the growing positions of the largest banks have a certain potential for intensification in the future.

However, even active consolidation is not always able to cause substantial increases of concentration. Consequently, consolidation may, under certain conditions, limit its own positive impact at an individual bank level or, under different circumstances, be the reason for realization of positive (or negative) consequences of concentration. In order to understand what consequences may cause consolidation which the NBU mentions in paragraph A.6 (xi) of the NBU, 2015 regarding Improvement of Legislation Regulating Mergers of Financial Sector Participants, it is advisable to determine first: a) what is consolidation?; b) how to measure concentration; and c) what are the relationships between them?

To answer these questions, the authors made a retrospective study of dynamics of certain bank concentration indicators from 1998-2015 and a comparative analysis of banking concentration levels in Ukraine and other countries of the world. The differences in concentration levels and competition among banks on various banking products markets and underlying reasons for growing concentration indexes in the course of cleansing and transformation of Ukraine's banking system were discussed. The problems of different sensitivity of concentration indexes to the number of banks, consolidation processes and structural changes in the banking system driven by different speeds of organic growth and capitalization of financial institutions were reviewed.

The goal of this article is to provide a comprehensive assessment of trends, reasons, and possible magnitude of increasing concentration of Ukraine's banking system and provide, based on assessment results, recommendations for the financial regulator on how to improve monitoring of concentration in the banking sector and better regulate consolidation processes in bank mergers and acquisitions.

Article's structure. Section 2 offers an overview of literature. Section $\mathbf{3}$ describes theoretical approaches to the study of consolidation and concentration processes, and it contains a number of assumptions lying at the core of this study. Section 4 explains the methodology for measuring concentration level. Section $\mathbf{5}$ provides key empirical results that provide answers to the following questions:

a) Is Ukraine's banking system concentrated?

b) What has been driving the growing concentration in 2014-15?

c) How concentrated is Ukraine's banking market in comparison with other countries?

d) What is the level of concentration of particular banking products markets?

e) How may the exit of banks affect concentration?

f) Do regulators need to limit further mergers?

Section 6 features recommendations for the NBU and the AMCU based on the comparison of theoretical conclusions, international experience, and empirical results obtained by the authors. Section 7 contains general concluding remarks. 


\section{Overview of literature}

For the past few decades, the problem of consolidation and concentration of banking systems has been actively studied by foreign scholars. The interest of researchers and regulators in this problem stems from deregulation, globalization, and integration of financial services markets, and later from the substantial effect that transnational banks established as a result of consolidation had on the unfolding of the global financial crisis of 2007-2009.

An in-depth analysis of methodological approaches to calculation of concentration and inequality indexes can be found in the works by Tirole (1988), Hay (1991), Florian (2014), Hall \& Tideman (1967), Atkinson \& Micklewright (1992), Jacquemin (1975), and Hirschman (1964). The range of the HHI is set in international legislative acts regulating horizontal mergers: EC (2004), U.S. (1992, 2010). A historical overview of consolidation and concentration processes occurring in foreign banking systems is offered in the works by Pohl et al. (2001), Kalashnikov (2007), and Kozak (2013).

Positive consequences of banking market's consolidation in the form of increasing effectiveness of industries were studied by Tirole (1988), Hay (1991), and Berger (2000) who emphasized that concentration can increase banks' revenues due to the scale effect, higher degree of price control, and better diversification opportunities opened to larger-size banks. As empirical studies prove, high concentration facilitates access to debt capital markets for profitable firms. Most scholars agree that concentration of bank capital is a global trend that has a number of significant positive effects, such as growing effectiveness, risk diversification, cost reduction and increased quality of products.

Negative consequences of concentration were tested in a broad range of empirical studies concerning the relation between concentration and financial strength. De Nicolo et al. (2003) discovered that consolidation increases risks for large financial conglomerates, while excessively concentrated banking markets are exposed to a higher degree of systemic risk. The "concentration-fragility" relation at the global level was studied by Beck et al. (2007), Allen \& Gale (2004), and Claessens \& Laeven (2003); based on EU data - Pawlowska (2015), Fiordelisi (2009), and ljtsma (2015); and in Asia - Abbasoglu (2007), Yaldiz (2010), and Rath et al. (2014). Consolidation processes, concentration, and market organization within Ukraine's banking system were studied by Stephan et al. (2012), Prozorov (2003), Koretska (2014), and others.

Works devoted to large banks are closely related to the problem of banking concentration: De Nicoló et al. (2003), Haldane (2012), Laeven et al. (2014), Vickers (2012), and Liikanen (2012). Growing concentration, especially if driven by increasing inequality, may turn the largest banks into institutions "too big to fail" that do not foster competition, are prone to heightened moral hazard and excessive risky activity, may be inclined to breach generally-accepted market discipline, and are capable of putting pressure on public authorities.

Substantial interest in the matters of capitalization, concentration, and consolidation is present in the works discussing the optimal size and organization of the banking market. Thus, answering the question "is there an optimal size of financial sector?", Santomero et al. (2000) arrives at the conclusion that highly-capitalized banks can better perform their key role on orders from their creditors (depositors): monitoring borrower solvency. Hence, the significance of bank capital and regulation of its adequacy is required to ensure efficient intermediation of the cross-flow of credit resources from household sector to real sector of economy.

Discussing the search for the banking market's optimal organization, Amable et al. (2002) point out the role of mergers and acquisitions as bankruptcy substitutes in the course of the banking system's transformation process, and compare the effect of high concentration of oligopolistic and low concentration of competitive banking markets on their financial strength. Among important consolidation studies, the works by Group of Ten (2001) offering comprehensive analysis of reasons for and consequences of consolidation of financial services markets, English (2002) studying its effect on monetary policy, and Uhde (2009) studying the effect of consolidation on financial stability in Europe are worth noting. Key theories of motives behind mergers and acquisitions (synergy theory, agency theory of free cash flow, and hubris theory) and a number of empirical studies devoted to their testing are reviewed in detail in the book by Rudyk, Semenkova (2000).

\section{Theoretical assumptions}

Concentration and consolidation play a key role in many empirical studies, but still require clear formulation in view of discrepancies in the interpretation of terms. In this article, we go by the definition set out by Group of Ten (2001), according to which consolidation of the financial services sector involves the resources of the industry becoming more tightly controlled, 
either because the number of key firms is smaller or the rivalry between firms is reduced. Therefore, consolidation becomes a consequence of the processes, which are also referred to as the following: a) unifying reorganization (mergers and acquisitions) of existing banks, b) growing volumes of market leaders, or c) market exit of weaker institutions. We have to make this clarification, because the term "consolidation" is often used in a narrow sense at an individual level and applied solely to bank mergers and acquisitions.

The term "consolidation" means market (industry-wide) concentration, i.e., the division of market shares. In our case, we study the banking services market with bank assets as the key characteristic of volumes (in a general case), whereas we used other relevant indicators to calculate concentration of the banking market's product segments (e.g., credit or deposit).

Consolidation and concentration are closely related. Moreover, concentration is regarded as a result, a certain marker of consolidation processes, and one of the factors determining the banking system's competition level and financial strength. The possibility of growing concentration makes the assertion regarding a positive effect from consolidation not quite obvious and requiring substantiated proof, assessment of side effects, and communication of results to the public. First, one has to calculate, in quantitative terms, the range of concentration increase after the reduction of banks, which has been done in this article. Second, not denying the existence of positive effects from a reduction in the number of banks, it is worth comparing them to possible threats to the system: Would consolidation not result in the excessive growth of concentration threatening to monopolize the sector? What effect would consolidation have on increasing inequality? What consequences may result from raising barriers to entry for new participants? To answer these questions, we will attempt to calculate the effect from the sector's consolidation on its concentration since the beginning of 2014 and compare it with the effect of increasing inequality - the growing heterogeneity of market participants' market shares.

Hay (1991) considers concentration as one of the three primary characteristics of market organization, on par with savings from scale and product differentiation, which determine market type depending on their combination. Thus, low values of all three components point to structural market conditions similar to sophisticated competition. When the scale and concentration of an industry are low while the product differentiation is high, it produces a type of monopolistic competition with a certain level of pricing freedom. High scale effect and market concentration without product differentiation prove the existence of a homogeneous oligopoly, whereas a combination of maximum values of all three parameters leads to the establishment of a monopoly or differentiated oligopoly that minimizes pricing and intensifies non-pricing competition by forming loyalty to brands via marketing and advertising campaigns and by offering unique product lines.

In addition to pricing advantages gained by an oligopoly from savings on the scale, a high concentration of the banking market may create an additional entrance barrier preventing market penetration by new banks which will have to make substantial outlays to win customer loyalty. Moreover, high concentration combined with product differentiation increases the probability of cooperation and collusion among an oligopoly's major participants; combined with high entrance barriers, that can increase the profit norm and margin for banks but may adversely affect the rest of the banking system's stakeholders.

Contemporary theories of market concentration are based on the literature of the New Empirical Industrial Organization (NEIO) featuring empirical testing of hypotheses by using aggregated industrial data or individual data at the firm level. As we said earlier, according to the NEIO methodology, the level of market competition does not always depend solely on concentration measures but envisages accommodation of such market characteristics as dynamics of entrance barriers and intensity of firms' exit (Pawłowska, 2015). Therefore, the level of competition in the banking market changes mainly via two channels: consolidation and regulatory requirements (in particular, concerning capital) setting barriers to the entrance of new participants.

It is worth noting that when measuring concentration of the banking market's assets, the following assumptions were made in this article:

1) Non-differentiation of products, because product differentiation may lead, even in the conditions of low concentration, to the formation of a segmented monopoly or oligopoly;

2) Evenly-spread geographical location of branches: this way, we abstract away from the possible existence of regional or local monopolies, the risk of whose appearance is objectively minimized with the development and wider penetration of online banking;

3) Absence of collusion and strategic alliances among banks, which de-facto increases the level of concentration as banking unions have higher market shares. For the purposes of further studies and monitoring, it is advisable to take into account that a more precise measurement of concentration should not be confined within the legal framework of banks operating for common strategic goals and have common or related owners. 
Because of the difficulties with the use of Ukrainian empirical data series on the way towards adequate assessment of the effect of concentration on competition, profitability, or financial risks, for the purposes of this study we will confine ourselves to the analysis of reasons for and forecasts of future levels of banking concentration in Ukraine. Calculation of dependence between concentration and financial strength is not a subject of this study because a relatively short series of empirical data, a strong cyclical nature, and the much greater effect of other factors prevent us from precisely assessing the effect of concentration on risks and effectiveness of the banking system. When determining potential positive and negative consequences of concentration, we will use basic theoretical conclusions of mainstream economic science and the best regulatory practices of understanding the levels of low or threatening concentration. Our assumptions are based on generally-accepted theoretical and empirical results incorporated in EU and U.S. antimonopoly legislation. According to conclusions of most studies and the logic of regulatory acts, low concentration is incompatible with monopoly, yet it lowers effectiveness of the banking system. On the other hand, excessive concentration threatens with adverse effects from monopolization while at the same time stimulating the growth of effectiveness.

\section{Methodology and data}

How can the level of the banking market's concentration be measured? To do that, there is a wide choice of methods and indicators that all have their upsides and drawbacks. However, before selecting the most efficient concentration indexes, we should make a number of additional assumptions by answering the general questions regarding quality of base data Hay (1991):

1) What business unit classification method is best for use on the banking services market?

2) How was the size of every bank measured?

3) How is the total volume of banking (general/deposit/credit) market calculated?

First, the studied market will include banks whose indicators were published quarterly in statistical bulletins disclosing financial statements of Ukrainian banks. Theoretically, credit unions, pawnshops, financial companies, and life insurance companies may compete with banks and affect concentration indexes of particular markets for deposit and credit products. However, considering the lack of a long time series (and also a negligible market share), the segment of non-bank financial intermediaries was not included to credit and deposit markets.

Second, to evaluate the size of every bank (i) as of the beginning of a quarter $(t)$, we used the asset volume data $\left(\right.$ assets $\left._{i t}\right)$, and to calculate the bank's share of particular product markets: amount of loans issued to and deposits received from retail and corporate banking businesses (ret_loans, corp_loans, ret_dep, corp_dep, respectively). Balance or authorized capital may serve as ancillary base indicators for concentration calculation purposes; however, their use often distorts the actual market organization as equity may have negative value or share of authorized capital on the balance sheet may vary depending on banks' internal policy on capital formation.

Third, we calculated market volume as the sum of corresponding indicators of every bank's financial statements as of the beginning of the quarter. Thus, the total volume of banking market in terms of assets was:

$$
\mathrm{A}_{\mathrm{t}}=\sum_{i=1}^{n} \operatorname{assets}_{i t}
$$

Therefore, $s_{i t}$ is the market share of $i$-th bank as of the date $t$ :

$$
s_{i t}=\frac{\operatorname{asset}_{i t}}{A_{t}} \times 100 \%
$$

Considering the high aggregate share of insolvent (de-facto removed from market) banks, calculation of market volume for three quarters of $\mathbf{2 0 1 5}$ did not include banks placed under temporary administration. In the preceding periods, market volume was calculated for all banks mentioned in NBU reports. Therefore, our aggregate indicators may insignificantly diverge from certain aggregated official data. Nevertheless, it cannot affect the accuracy of our study.

To measure concentration in banking systems, we used traditional indicators which proved their effectiveness but, however, not without their strengths and weaknesses. Let's go over the most popular ones. 
$-C R_{n}$ (n-firm Concentration Ratio): aggregate market share of $\mathrm{n}$ largest banks:

$$
C R_{n}=\sum_{i=1}^{n} s_{i}
$$

where $s_{i}$ is the market share of the $i$-th bank, $\mathrm{n}$ is the number of largest banks ranked in the descending order of their market share. The most popular concentration indexes are $C R 3, C R 4, C R 5, C R 8$ and $C R 10$. The sum of $C R_{n}$ indexes for the entire $n$ series as of the date $t$ is $(1 ; k)$, where $k$, the number of active banks on the market, forms a concentration curve. We can use the concentration curve to calculate the more seldom-used $C R$-inversed indicator: the number of banks holding the $s$ market share set as a percentage.

- HHI (Herfindahl-Hirschman Index): the sum of the square of the market shares of every bank in the system, i.e.:

$$
H H I=\sum_{i} s_{i}^{2}
$$

where $s_{i}$ is the market share of the $i$-th bank. Considering the availability of individual data for every bank in the system, the authors have calculated "full-fledged" HHIs, whereas in the conditions of a lack of required data, these indexes may be calculated on the basis of indicators from the top 50 firms operating on the studied market. According to the requirements of U.S. antimonopoly laws amended in 2010, a market shall be considered competitive if $H H I<1,500$; moderately concentrated if $1,500<H H I<2,500$; or highly concentrated if $H H I>2,500$ (US(2010)). Prior to 2010, the official $H H I$ range in the United States for moderately concentrated markets was lower: between 1,000 and 1,800 (US(1994)); today, a similar range in the EU is between 1,000 and $2,000(E C(2004))$.

- Hannah-Kay Index: other HHI-related concentration indexes of the type:

$$
R=\sum_{i} S_{i}^{\propto}
$$

where $s_{i}$ is the market share of the $i$-th bank; $\alpha$ is an elasticity parameter indicating weight given to the largest banks vis-à-vis the smallest. If $\alpha=0$, then $R=\max (i)$, i.e., the concentration is determined only by the number of banks on the market while the inequality factor is disregarded. If $\alpha$ grows, the weight of large banks' effect on the concentration index substantially increases, which can make sense if a study is focused on the banks' inequality aspect. Most scholars use the standard value of $\alpha=2$, for which $R=H H I$ (Hay, 1991). The varieties of this index are THI (Hall-Tideman Index), ECI (Entropy Concentration Index), etc. (Jacquemin, 1975).

b) Inequality indicators are traditionally used to measure concentration, because they point out the inequality in distribution of market shares: inequality that, together with a low number of banks on the market, may become a reason for substantial concentration. However, the inequality per se does not depend on the number of market participants, and therefore, it provides only an indirect indication of concentration.

- Gini Coefficient: an indicator of the unequal distribution of bank volumes derived from the Lorenz curve (Figure 4). If assets were equally distributed among all banks on the market, the Lorenz curve would appear as the diagonal of the unit square. As inequality among banks grows, it attains a convex shape below the diagonal of equal distribution and shows the dependence between $p$, share of the number of banks ranked by asset growth, and $L(p)$, the cumulative market share of these banks. The Gini Coefficient represents the ratio of the area of the shape between the curve and diagonal to the total area of the triangle. The maximum value of Gini $=1$, which would show the absolute inequality when one largest bank possesses all assets in banking system; the minimum value of $\operatorname{Gini}=0$, which is attained upon the absolute equality of all banks.

- Atkinson Index: a group of inequality coefficients that includes the sensitivity parameter $(\varepsilon)$ varying within the range from 0 to infinity and enables a shift in the focus of analysis on distribution of the smallest market participants (Atkinson, 1992). We have calculated the Atkinson Index as an ancillary indicator with the standard value of $\varepsilon=0.5$.

- GE (Generalized Entropy Index): a group of inequality indicators that includes the preset sensitivity component $(\alpha)$ which, when increasing, increases the sensitivity of $\mathrm{GE}(\alpha)$ to inequalities in distribution among the system's largest banks. For the purposes of this work: $\mathrm{GE}(0.5)$, where $\alpha=0.5$. 
- Theil Index: a particular case of the entropy index:

$$
\text { Theil }=G E(1)=\sum_{i} s_{i} \log s_{i} .
$$

- Var (Variation Coefficient): the ratio of the standard deviation of assets (or other bank size indicators) to the average mean distribution of their values.

- $\sigma^{2}$ (variance of bank size logarithms): squared standard deviation of logarithms. The $H H I$ may be expressed as a function of the number of banks $(n)$ and variance of market shares $\left(\sigma^{2}\right)$, which for a certain $\mathrm{HHI}$ form the uniform concentration curve (Hay, 1991):

$$
H H I=n \sigma^{2}+\frac{1}{n}
$$

Apparently, the inequality indicators like variance, variation, or Gini coefficients are rather supplementary than full-fledged measures of concentration, because they do not take into account the number of banks on the market. Thus, the Gini coefficient will be equal to zero for systems with both 2 and 200 banks of equal size, despite the greater concentration of the former scenario of market organization. On the other hand, changes in heterogeneity of market organization help better understand the reasons that cause growth or decline of concentration, because in combination with the increase in the number of banks, they determine its dynamics as formula 7 shows.

The aforementioned coefficients became key indicators for descriptive analysis of panel and cross-sectional data, aimed at complete understanding of concentration dynamics on banking products markets and relative concentration indices vis-à-vis EU states. Methodologies of the rest of the empirical studies were described in paragraphs where pre-calculated concentration and inequality coefficients served as both dependent and independent variables.

For the majority of empirical calculations, we used the NBU data containing individual indicators of banks' quarterly financial statements for the period from 1 January 1998 to 1 October 2015. In addition, we used the European Central Bank's data concerning $\mathrm{HHI}$ and CR5 for particular EU states as of 1 January 2015.

\section{Empirical results}

\section{a. Is Ukraine's banking system concentrated?}

The first objective of our empirical study, which, once fulfilled, could allow us to move to the next itemization and forecasting phases, was to measure the existing concentration level of assets in Ukraine's banking market and dynamics of concentration over the past decades. Overall, large firms operating on a concentrated market are prone to uncompetitive behavior, thus creating a systemic risk according to the so-called "structure-conduct-performance" paradigm. Therefore, the growth of concentration per $\mathrm{HHI}$ by more than 100 points in the conditions of a highly-concentrated market $(\mathrm{HHI}>2,500)$ or by 200 points for a moderately-concentrated market $(1,500<H H K<2,500)$ indicates a substantial increase of market force according to the U.S. antimonopoly law regulating horizontal mergers U.S. (2010). According to EU requirements, in the conditions of high concentration $(H H I>2,000)$ the critical limit for a competition-safe increase of $H H I$ is 150 points, whereas for moderate concentrations $(1,000<H H I<2,000)$, an increase rate of over 250 points is considered threatening EC (2004).

Therefore, in order to refute the myth concerning threatening levels of concentration and spreading together with its growth, we have tested the hypothesis regarding low concentration level of Ukraine's banking system by calculating the key concentration and inequality indicators.

Our HHI calculations point out a low concentration of Ukraine's banking market: during the period from 1 January 1998 to 1 October 2015, the average $\mathrm{HHI}$ was 454 points and standard divergence of indicators 119 . By the end of 3Q 2015, the $\mathrm{HHI}$ reached the maximum value of 836. Nevertheless, the overall banking concentration in Ukraine still remains low from the viewpoint of both stricter EU norms (1000) and softer U.S. norms (1500), fostering liberalization of mergers and acquisitions market.

Concentration level dynamics in Ukraine's banking system have four clearly-visible phases: 
Figure 1. $\mathrm{HHI}$ dynamics (in asset terms) of Ukraine's banking system 1 January 1998 to 1 October 2015

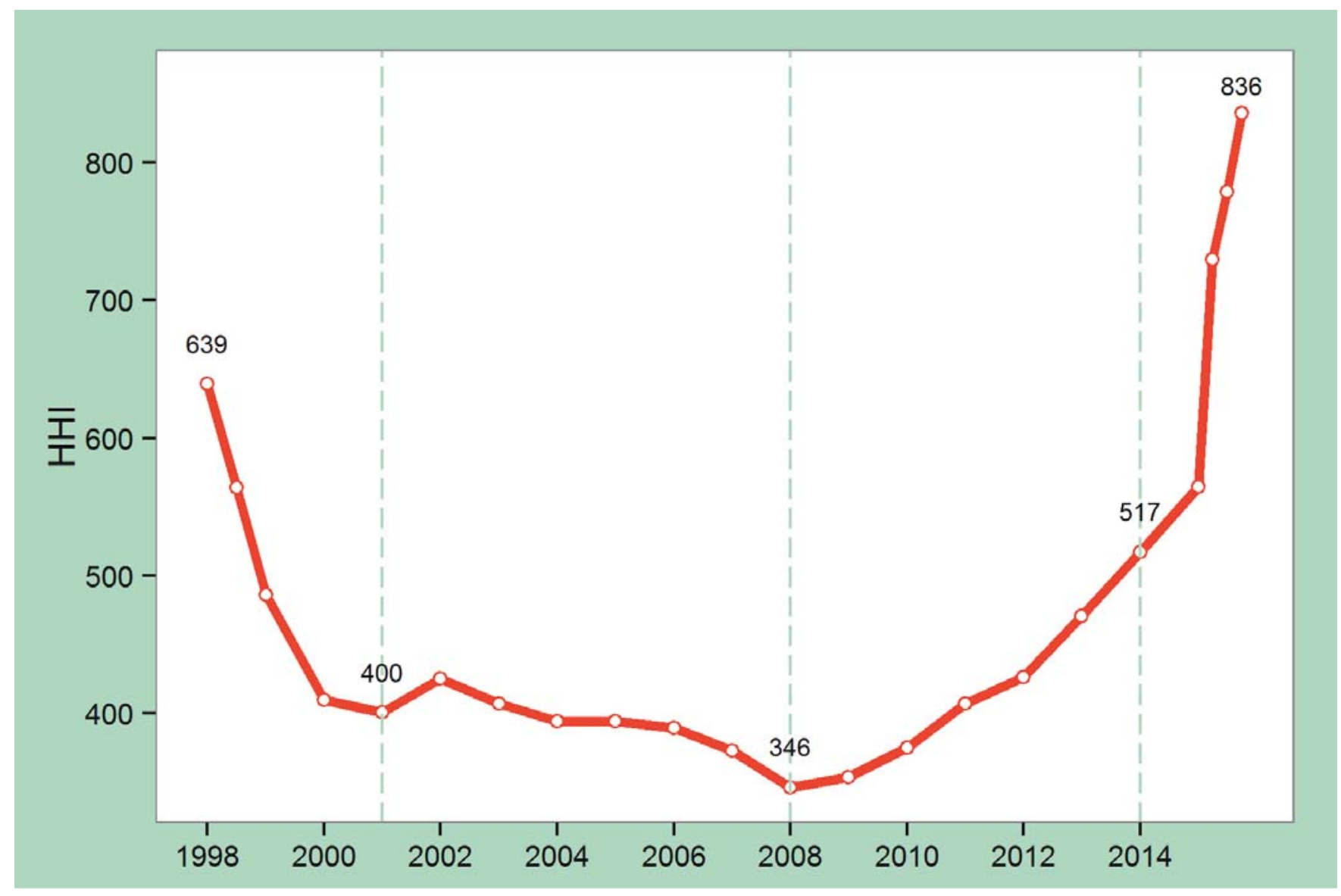

1) 1998-2001: HHI's sharp decline from 639 to 400 due to reformatting the market's organization and smoothening of inequality as a result of a series of liquidations, mergers and acquisitions, and growth of medium private banks with simultaneous shrinkage of market shares held by previous leaders - post-Soviet banks;

2) 2002-2007: HHI's gradual decline to 346. We assume that strengthening market positions of "middle-echelon" banks, particularly due to development of retail banking and influx of foreign capital, was the key driving force behind that;

3) 2008-2013: concentration growth to $H H I=517$ after a wave of liquidations in the wake of crisis and growing market share of market's leaders;

4) 2014-2015: accelerating growth to the peak value of $H H I=836$ due to closure of over 60 banks as part of the cleansing and transformation of the banking system.

As we can see, the dynamics of concentration levels in Ukraine do not coincide with the phases of economic cycle, because the 2008-2009 financial crisis was characterized by minimal HHIs, while the crises of 1998 and 2014-2015 featured local maximums of this index. Even if a correlation between instability and concentration was discovered, it should not be interpreted as the proof of a cause-and-effect relationship, because there are many additional factors that had an independent effect on concentration and economic growth. Correlation does not imply causation, especially since the conclusion is made on the basis of one country, without doing a wider, cross-border sampling.

Similar trends in the decline and growth of concentration, with the turning point occurring in 2008, are corroborated by dynamics of simpler concentration indexes $C R n$ (Figure 3). Maximum values of $C R 3=45 \%, C R 5=53 \%, C R 10=71 \%$ were recorded as of the end of 302015 (Table 1). Therefore, market concentration has been intensifying in recent years, although still remaining, as we will see, not very high in comparison with EU states. 


\section{Figure 2. Dynamics of concentration indicators (in asset terms) of Ukraine's banking system}

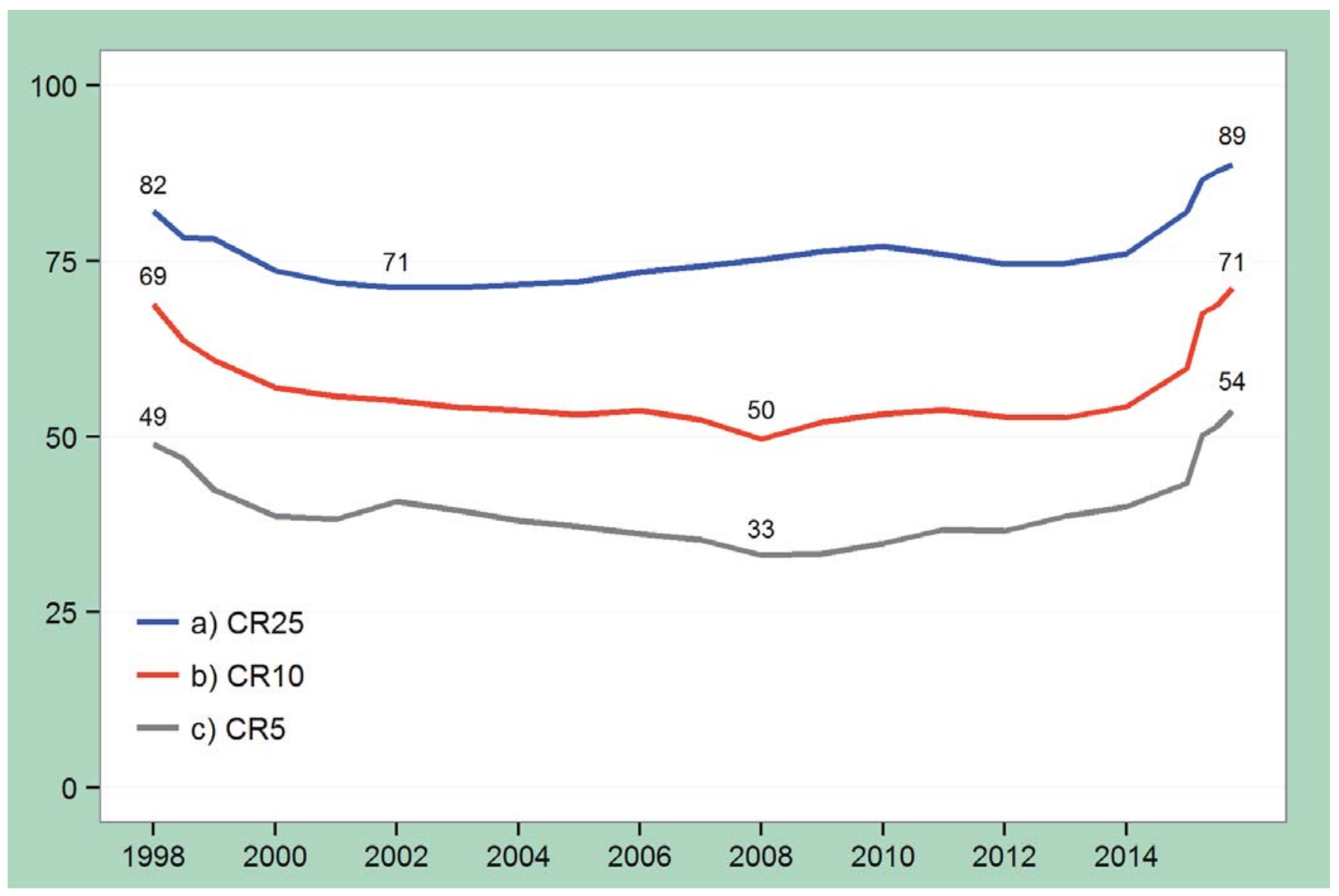

The widening spread between CR10 and CR25 from the beginning of 1998 to 2008 is worth noting: it confirms our assumption regarding the effect of increasing market potential of "middle-echelon" banks on declining concentration, for the strengthening of this layer of market participants smoothened the existing inequality between the largest and small banks. After the global financial crisis, this difference began to shrink, causing the reverse effect of increasing concentration. Having compared the empirical results, we came to the conclusion that the $H H I$ dynamics correlate with CRn (if $n<10$ ).

The growing curvature of the concentration curve with a simultaneous upward movement also proves the increasing banking concentration during 2000-2015 (Figure 3). The key factors that drove the increase were, first of all, the growing role of five market leaders with Ukrainian (including public) capital, thus causing the curve to rise along the $n=5$ line.

Second, the cumulative market share of banks of groups II and III per NBU classification has grown on a much larger scale, resulting in the maximum increase of concentration of the top 25 banks. Besides the spreading layer of large banks, the "tail' of the smallest banks that hardly had any effect on the level of concentration has disappeared in the course of formation of the banking system, as the proximity of curves along the $n=123$ line shows. Therefore, consolidation due to the exit of the smallest banks had an insignificant effect on concentration.

The change of the shape of the Lorenz curve over time points to a certain intensification of inequality among Ukrainian banks (Figure 4). The higher a degree of its curvature is, the greater the inequality in distribution of assets among banks, expressed by the Gini coefficient, becomes. In our case, Gini grew from 0.74 as of the beginning of 2000 to 0.83 as of 1 October 2015 (Table 1). The maximum growth has occurred in the total share of the first $10 \%$ of banks.

Despite the overall similarity, the trajectory of inequality indicators was somewhat different from the dynamics of concentration indicators. With the exception of variation, increasing inequality in market organization already began in the second phase, simultaneously with decreasing concentration, continuing from 2001 to 2010 (Figure 5, 6). 
Figure 3. Asset concentration curves for Ukraine's banking system as of $\mathbf{1 . 0 1 . 2 0 0 0}$ and 1.10.2015

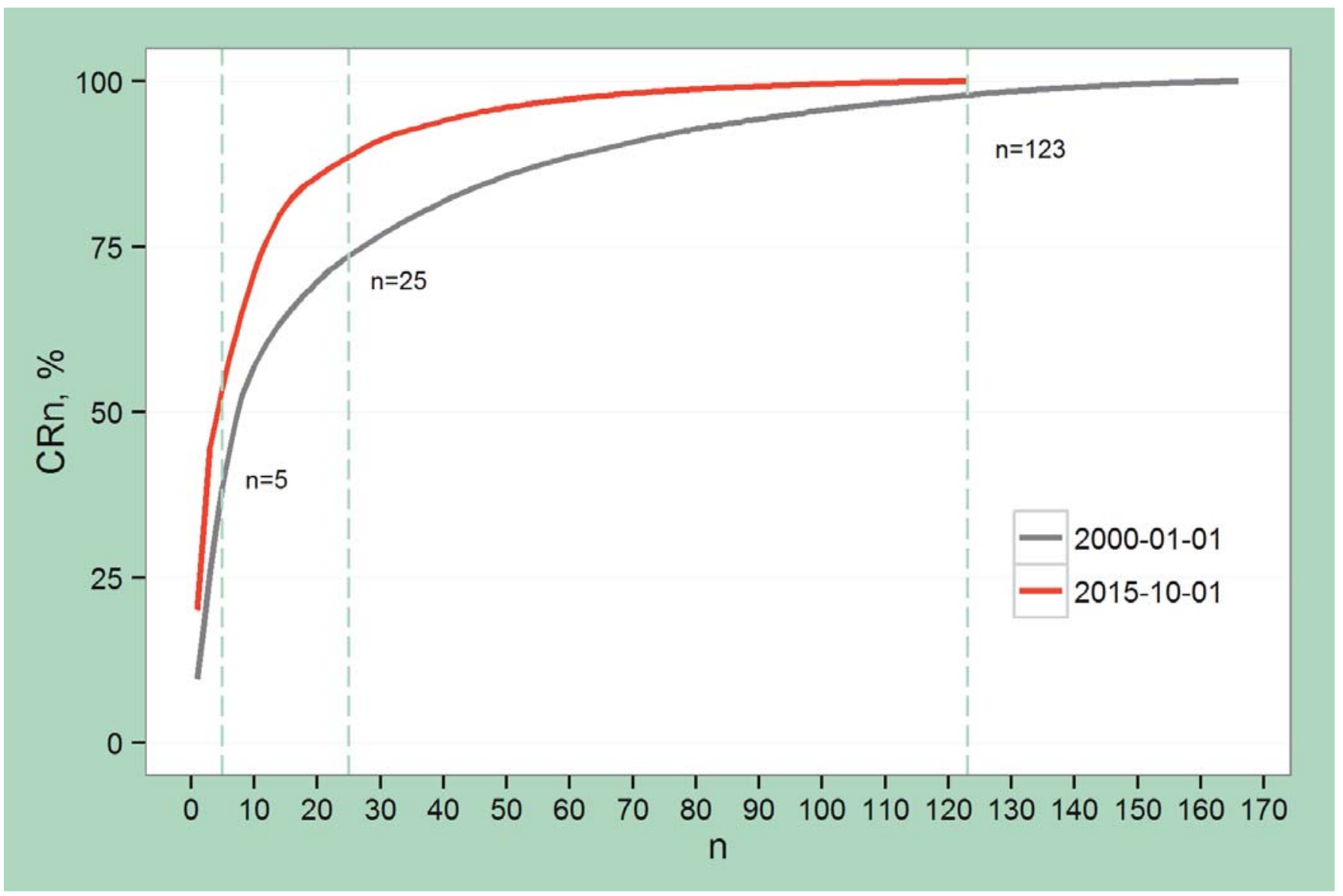

Figure 4. Lorenz curves for assets of Ukraine's banking system from 1 January 2000 (black curve) to 1 October 2015 (red curve)

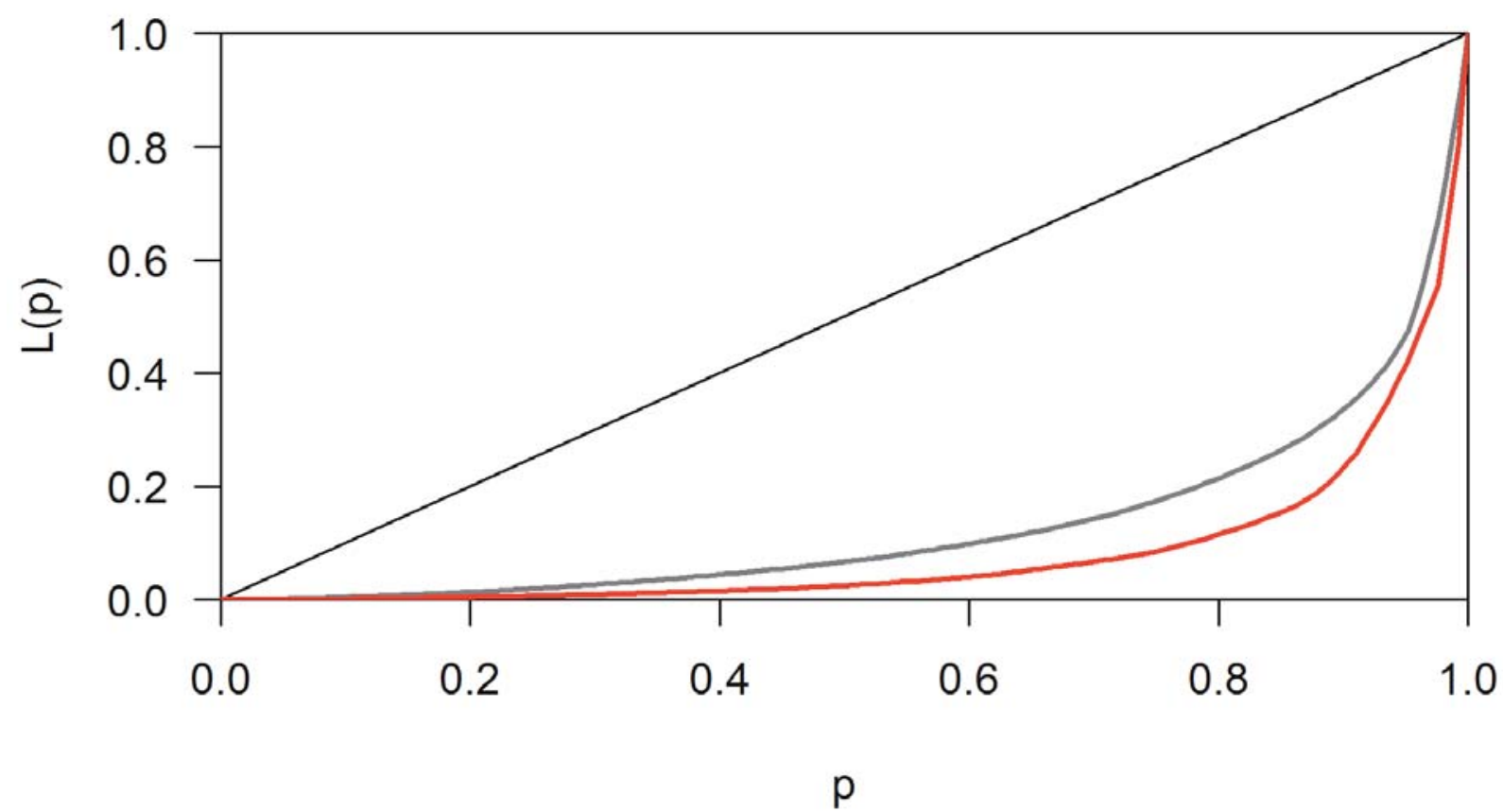


Figure 5. Dynamics of the Gini and Atkinson coefficients in asset terms

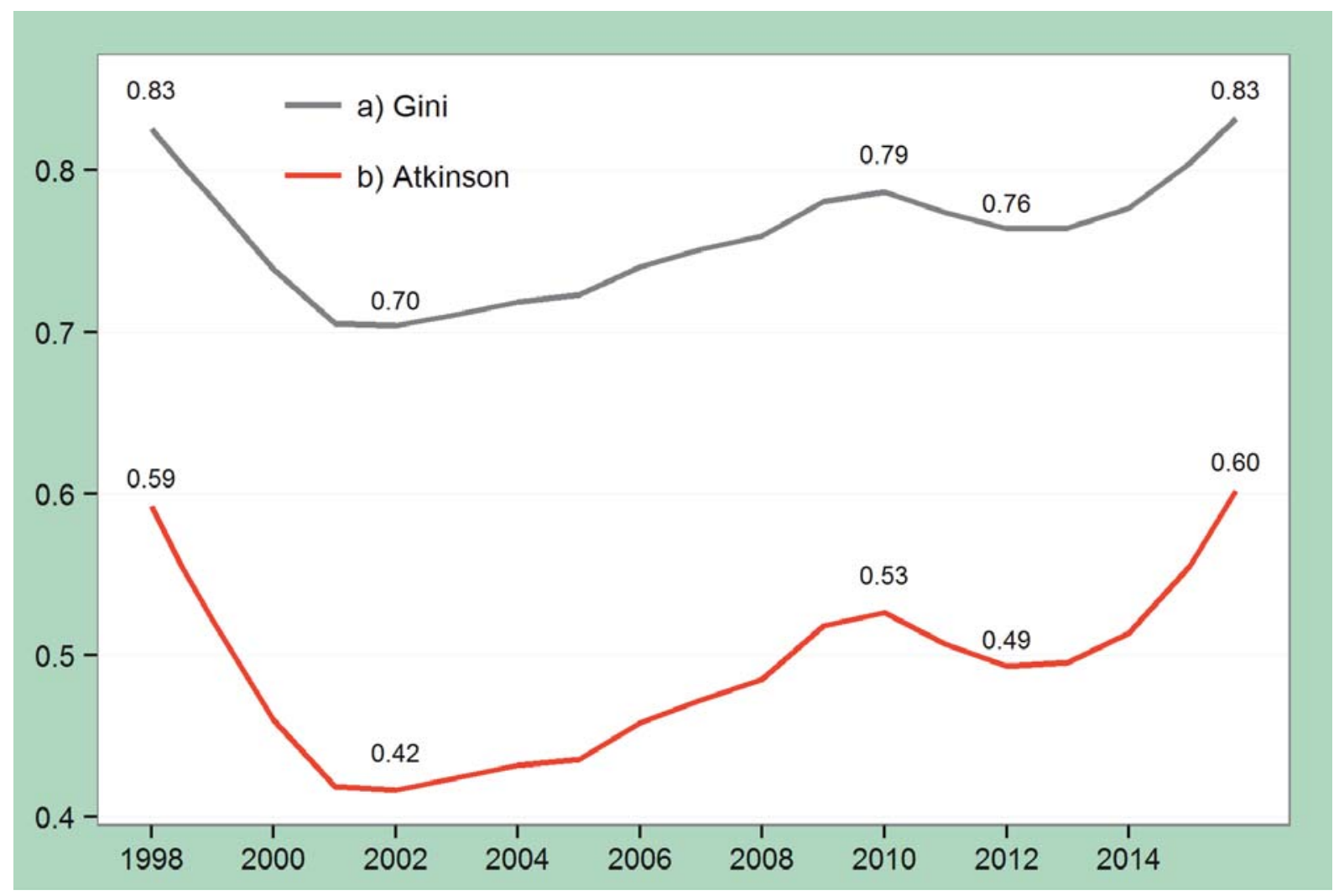

Figure 6. Dynamics of the Generalized Entropy, Theil, and Variation indexes in asset terms

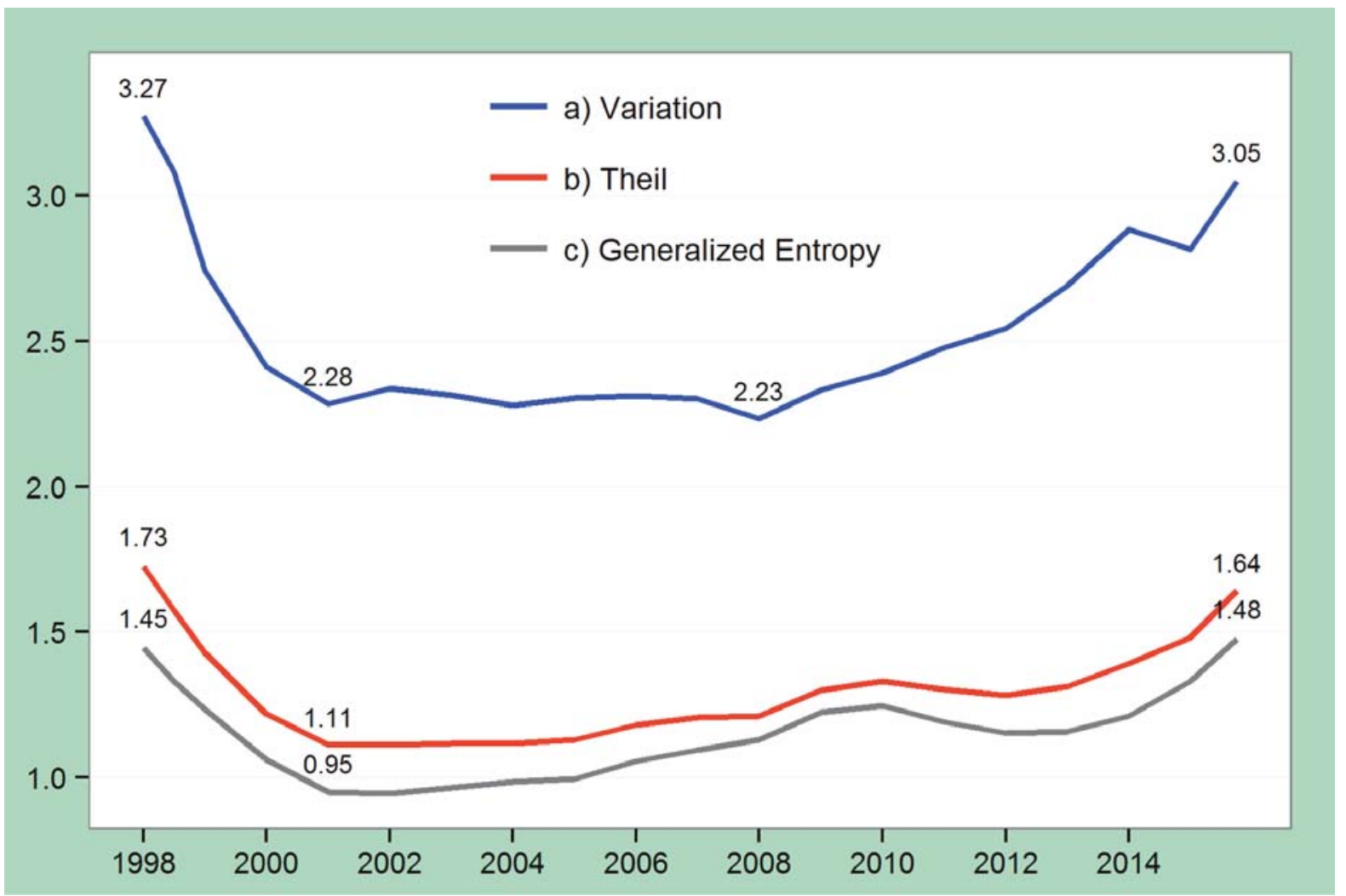


After an insignificant three-year decline, inequality within the system, expressed via the Gini, Atkinson, Theil, and Generalized Entropy indexes, began to grow starting from 1 January 2013, nearing the historical maximums of 1998 (Table 1).

Summing up the results of our retrospective analysis, we can see that the hypothesis concerning low concentration level was proved, pointing to the absence of barriers to consolidation. However, Ukraine's banking system is moving toward the minimum threshold of moderate concentration area envisaging a somewhat closer monitoring of horizontal mergers and acquisitions. For a more accurate interpretation of Ukraine's banking concentration indicators, we suggest an additional comparative analysis with similar indicators of EU states.

\section{b. What has been driving the growing concentration in 2014-15?}

Expert discussions sometimes mention a myth regarding concentration resulting from the growth of market leaders, especially the largest and two state banks, and the overall increase of market inequality as the banking system undergoes cleansing. To better understand the true reasons behind concentration dynamics during the 2014-2015 crisis, we made an additional factor analysis. The purpose of this analysis was to evaluate the relative weight of the following two key factors for HHI growth:

1) A bank's exit from the market due to classification as insolvent; and

2) The increasing inequality among remaining banks on the market.

Let's test the hypothesis stating that concentration of Ukraine's banking system after 1 January 2014 was growing due to a decrease in the number of market participants, not increasing inequality among banks.

To calculate the net effect on the $\mathrm{HHI}$ of the decrease in the number of banks during 2014 and the first 9 months of 2015, let's take a fixed number of banks, $n$, by selecting from all the banks that were active as of the beginning of 2014 only those that remained solvent as of 1 October 2015. For this number of future solvent banks, let's calculate hypothetic values of market shares as of the beginning of banking crisis:

$$
s_{i}^{*}=\frac{\operatorname{assets}_{i t}^{*}}{A_{t}^{*}}
$$

where $\mathrm{t}=1$ January 2014, assets $_{i t}^{*}$ - assets of the $i$-th bank that remained solvent after the crisis as of 1 October 2015, $A_{t}^{*}$ - aggregate value of assets as of 1 January 2014 for all the banks solvent as of 1 October 2015.

Apparently, if there were no banks that were later placed under temporary administration, hypothetic market shares of solvent banks would have been higher than the actual figures as of 1 January 2014. To ascertain the role played by the inequality factor, we'd like to know what the concentration indicators of our hypothetic banking system were as of the beginning of 2014 vs the most recent actual figures as of the end of 302015 (Table 2).

As our calculations show, the key concentration factor was the exit of problematic banks from the market (reduction of $\mathrm{n}$ ), whereas the inequality in distribution of assets $\left(\sigma^{2}\right)$ among active banks almost did not change. Concentration before and after crisis among banks that later turned out to be healthy was almost identical. For this hypothetic sample purged of the $\mathrm{n}$ reduction effect, the $\mathrm{HHI}$ was 835.7 , which is only 0.3 points lower than the actual figure of 836.0 as of 1 October 2015 . A factor analysis proves that the growth of the actual concentration per HHI during the period from 1 January 2014 to 1 October 2015 by 318.32 points (+99.9\%) was driven by the decline in the number of banks, whereas the effect of changes in inequality was $0.1 \%$.

As we can see, the key concentration factor was the exit of banks from the market (reduction of $n$ ), whereas the growth of the share of top 5 banks in assets of survived banks was insignificant. The effect of the decline in the number of banks on the growth of concentration coefficients CR4, CR5, CR10 and CR25 varied within the $80-85 \%$ range, while the effect from the strengthening of market positions of the largest banks that survived the crisis was only $15-20 \%$ (Table 2). Different effects from structural changes unrelated to market exit on the increase of the $\mathrm{HHI}$ and concentration indicators can be explained by the features of $C R_{n}$ concentration indexes, namely their insensitivity to dynamics of market shares of medium and small banks. The $\mathrm{HHI}$ does not have this flaw, comprehensively showing the overall level of fragmentation and inequality within the system. 
Figure 7. HHI growth from 1 January 2014 to 1 October 2015

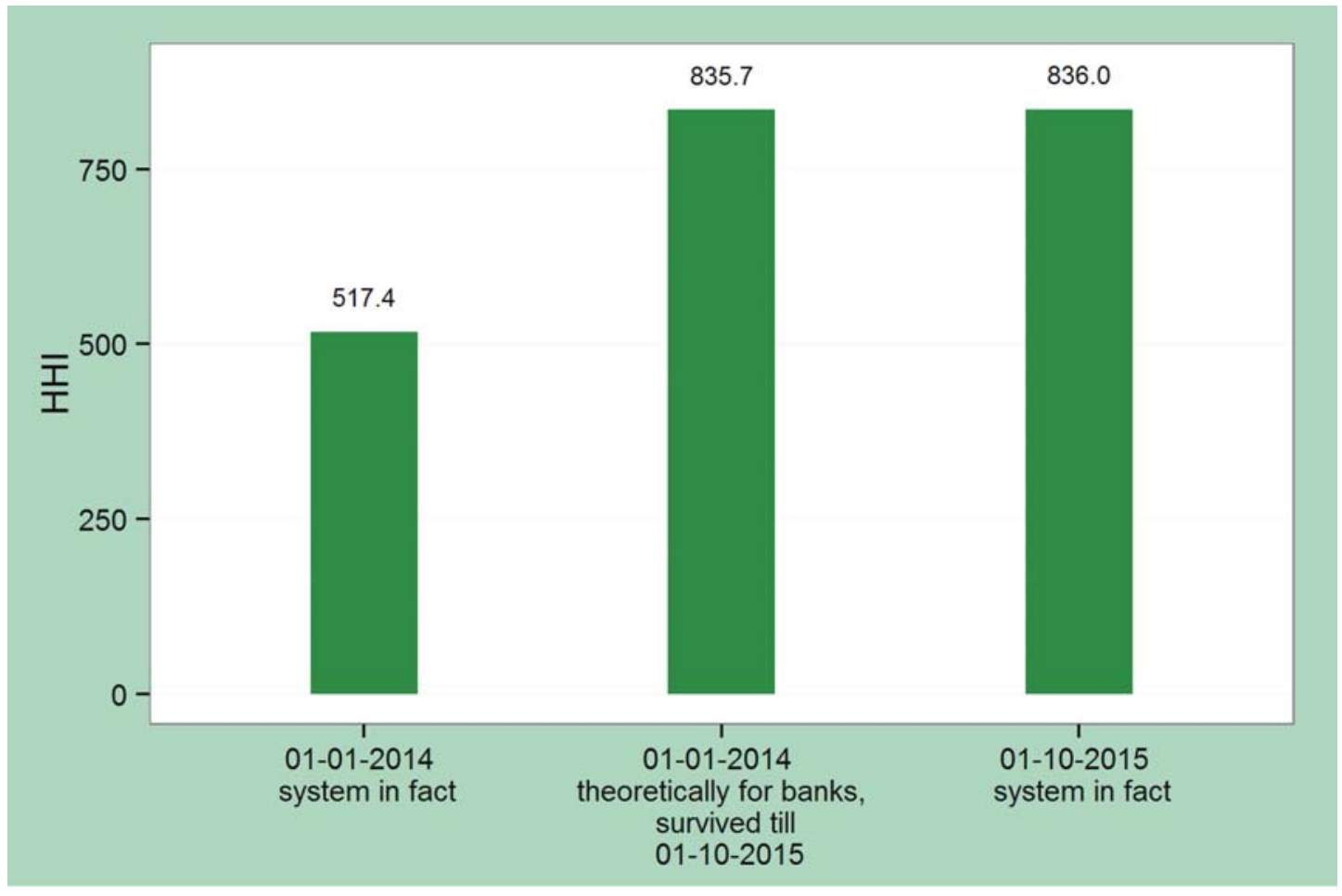

System's actual as of 1 January 2014; Theoretical for banks that avoided default between 1 January 2014 and 1 October 2015; System's actual as of 1 October 2015

Figure 8. CR5 growth from 1 January 2014 to 1 October 2015

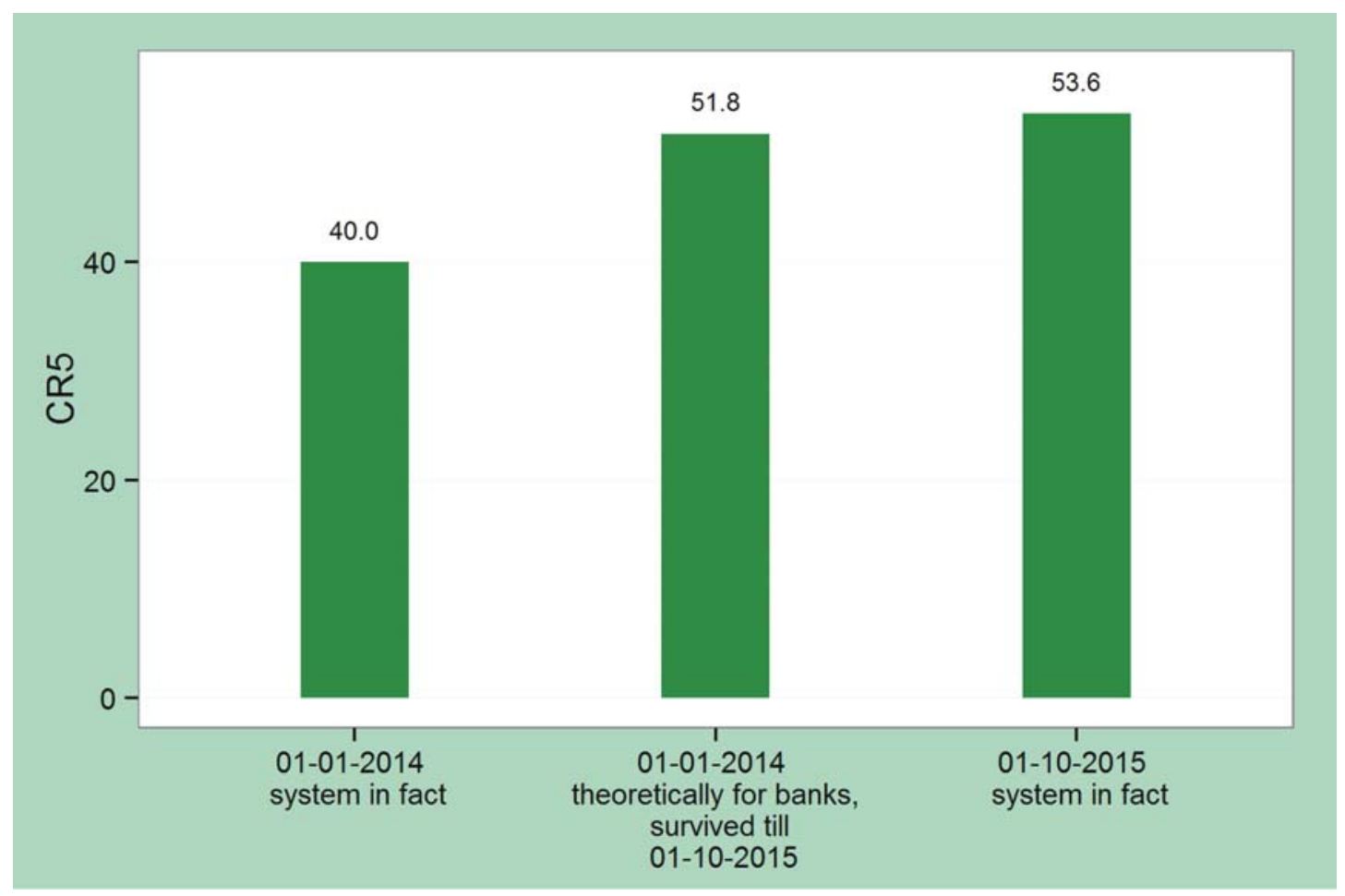

System's actual as of 1 January 2014; Theoretical for banks that avoided default between 1 January 2014 and 1 October 2015; System's actual as of 1 October 2015 
The growth of the inequality indicators (Gini, Atkinson, Entropy, and Theil) has occurred, in particular, in the subgroup of healthy banks. The effect from internal structural changes was $40-45 \%$, whereas the exit of banks from the market had a $55-$ $60 \%$ effect on the increase of inequality indicators. Nevertheless, the overall increase of inequality in the system after structural changes was not significant: the Gini index has grown by $7 \%$ to 0.83 , and the Atkinson index by $17 \%$ to 0.6 .

What makes interpretation of transformational processes in Ukraine's banking sector difficult is the different dynamics rates of both concentration indexes and inequality coefficients in the subgroup of healthy banks. Nevertheless, these differences are insignificant in comparison with the consolidation effect on concentration growth by the decrease in the number of market participants, the factor that contributed $99.9 \%$ to the $H H I$ increase. Therefore, the hypothesis regarding the decisive effect of banks' exit was confirmed and refuted the myth concerning the substantial contribution of increasing inequality to concentration growth.

\section{c. How concentrated is Ukraine's banking market in comparison with EU states?}

A more accurate interpretation of concentration and inequality dynamics in Ukraine's banking system requires comparison of domestic indicators with similar coefficients of other countries of the world. The myth regarding concentration threat may be finally dispelled only by comparing concentration with not only general normative indicators, but also with actual industry indicators of foreign countries. Thus, according to our hypothesis, Ukraine's banking market is insufficiently concentrated when compared to European countries.

To compare our calculated concentration indexes with European, we used the HHI and CR5 indicators of EU states as of 1 January 2015 (ECB, 2015). According to data by the ECB, market concentration in EU continues its upward trend that began in the pre-crisis period (Figure 9). The growth of concentration indexes in the EU, as in Ukraine, is driven mainly by a decline in the number of credit institutions.

Banking sectors with the maximum concentration are found in Estonia, Greece, and the Netherlands, whereas the banking systems of Germany, Luxembourg, Finland, Austria, and Italy are the least concentrated.

\section{Figure 9. Dynamics of banking concentration (HHI) in the Euro Area and EU}

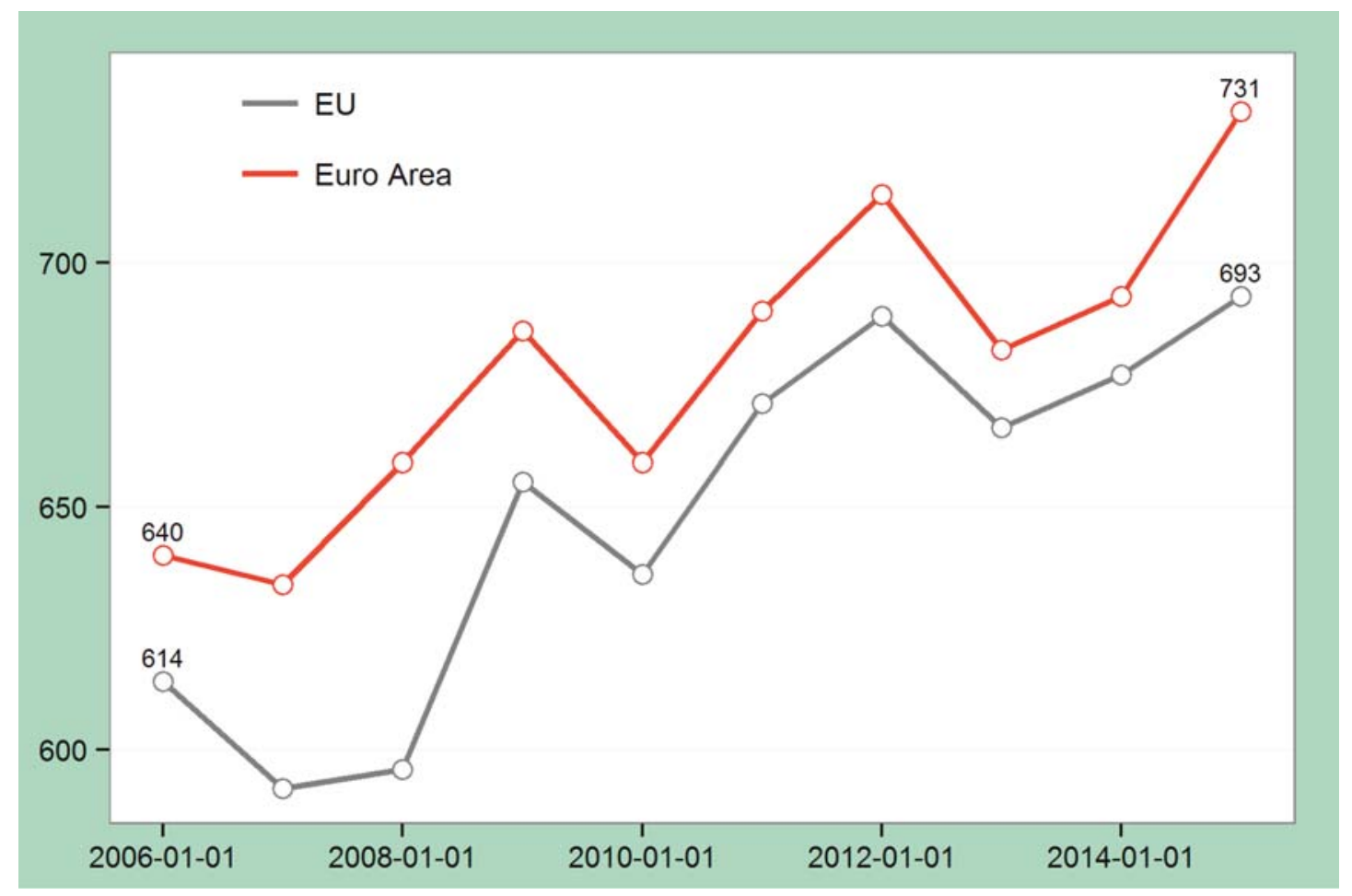

Source: $E C B(2015)$ 
At the same time, the present increase of concentration in Europe is driven by consolidation processes in France, Germany, and Spain, the countries that traditionally have more fragmented banking systems with strong sectors of savings and cooperative banks. Smaller EU states (except Austria, Ireland, and Luxembourg) have much higher concentration indicators than Ukraine (Figure 10).

Figure 10. Concentration level in banking systems of European countries $(H H I), 01.01 .2015$

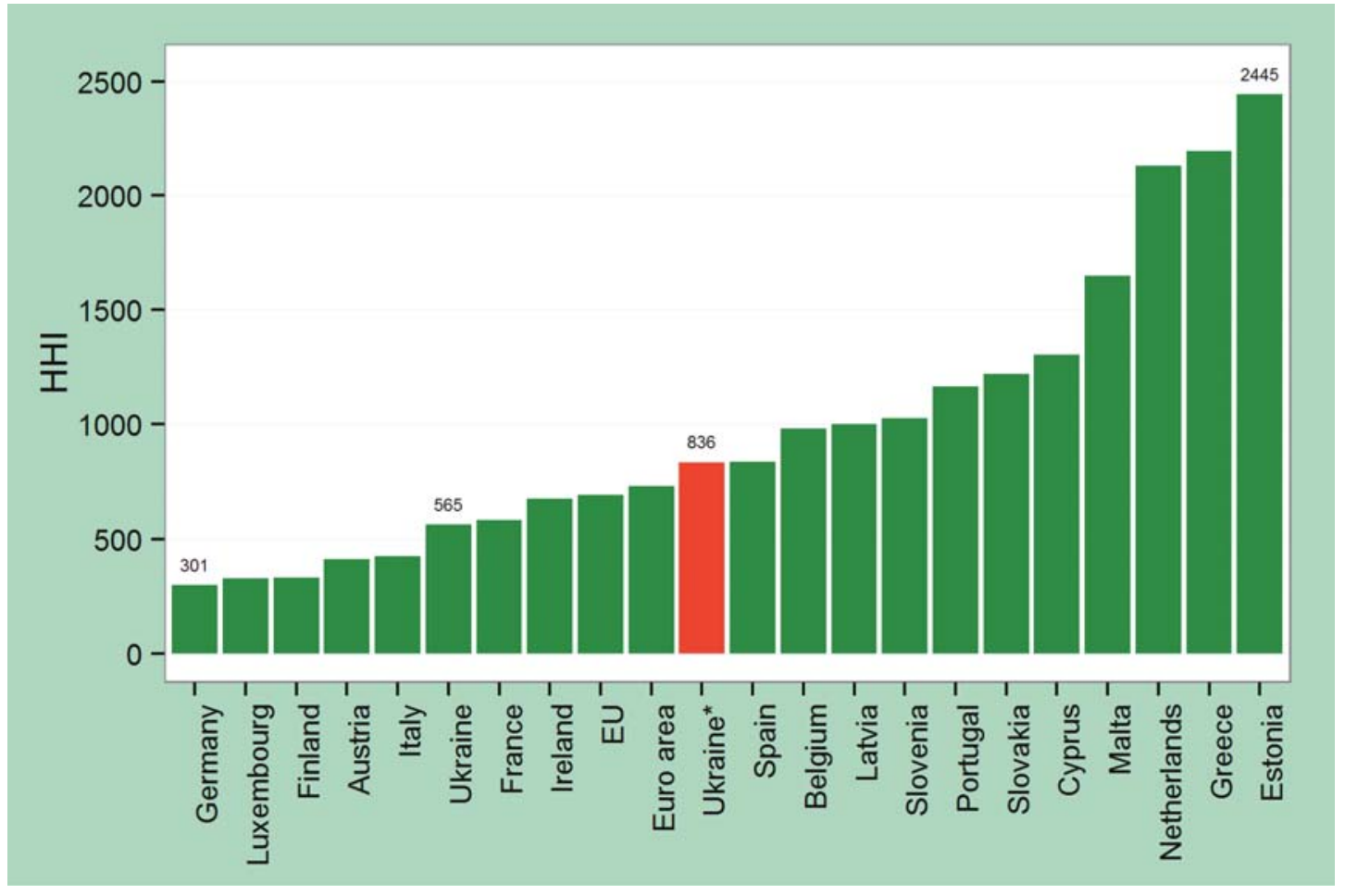

*- data for Ukraine as of 1 October 2015

Our descriptive analysis of cross-sectional data shows that as of the beginning of 2015, concentration in Ukraine was lower than Europe's average. Even today's historical maximums of the $\mathrm{HHI}$ in Ukraine are quite acceptable compared to many EU states. At the same time, Ukraine's HHI has exceeded contemporary average European figures, which suggests closer regulatory attention to consolidation processes and development of preventive instruments that would foster positive consequences, such as growing effectiveness and affordability of financing, while at the same time minimizing systemic risk and protecting rights of financial services consumers.

Overall, as of the beginning of 2015, market concentration (measured by the share of assets of five largest banks, CR5) varied from 95\% in Greece to 32\% in Germany and Luxembourg. From the viewpoint of CR5 change during 2008-2014, the banking sector has trended toward growing concentration in many EU states, especially those undergoing profound banking restructuring processes: Greece, Spain, Malta, Lithuania, etc. Concentration in other large economies, such as Germany and Italy, has increased during that time, whereas concentration declined in Estonia, Belgium, and Slovenia (ECB, 2015).

Multidirectional dynamics of concentration in EU states shows that the European trend toward increasing concentration is not completely unambiguous, while the growth of averaged indicators was driven, to a large degree, by the greater weight of national economies with a positive increase and by a substantial potential for concentration considering historical fragmentation of their banking systems.

The reasons for the surge in banking concentration in Ukraine, like in Germany and Italy, are also related to low starting levels and substantial growth opportunities; however, the growth rate may significantly decline after entering the moderate concentration area. Therefore, it would be erroneous to directly extrapolate today's concentration rate of Ukraine's banking market onto future periods. 
In terms of the aggregate share of assets of the 5 largest banks, Ukraine again ended up below EU's average, still substantially climbing in ranking during the year. By the end of 3Q 2015, Ukraine's CR5 indicator was higher than the corresponding banking market concentration index in Euro Area countries as of the beginning of 2015 (Figure 11).

\section{Figure 11. Asset concentration indexes of top 5 banks (CR5) in European countries, 1 January 2015}

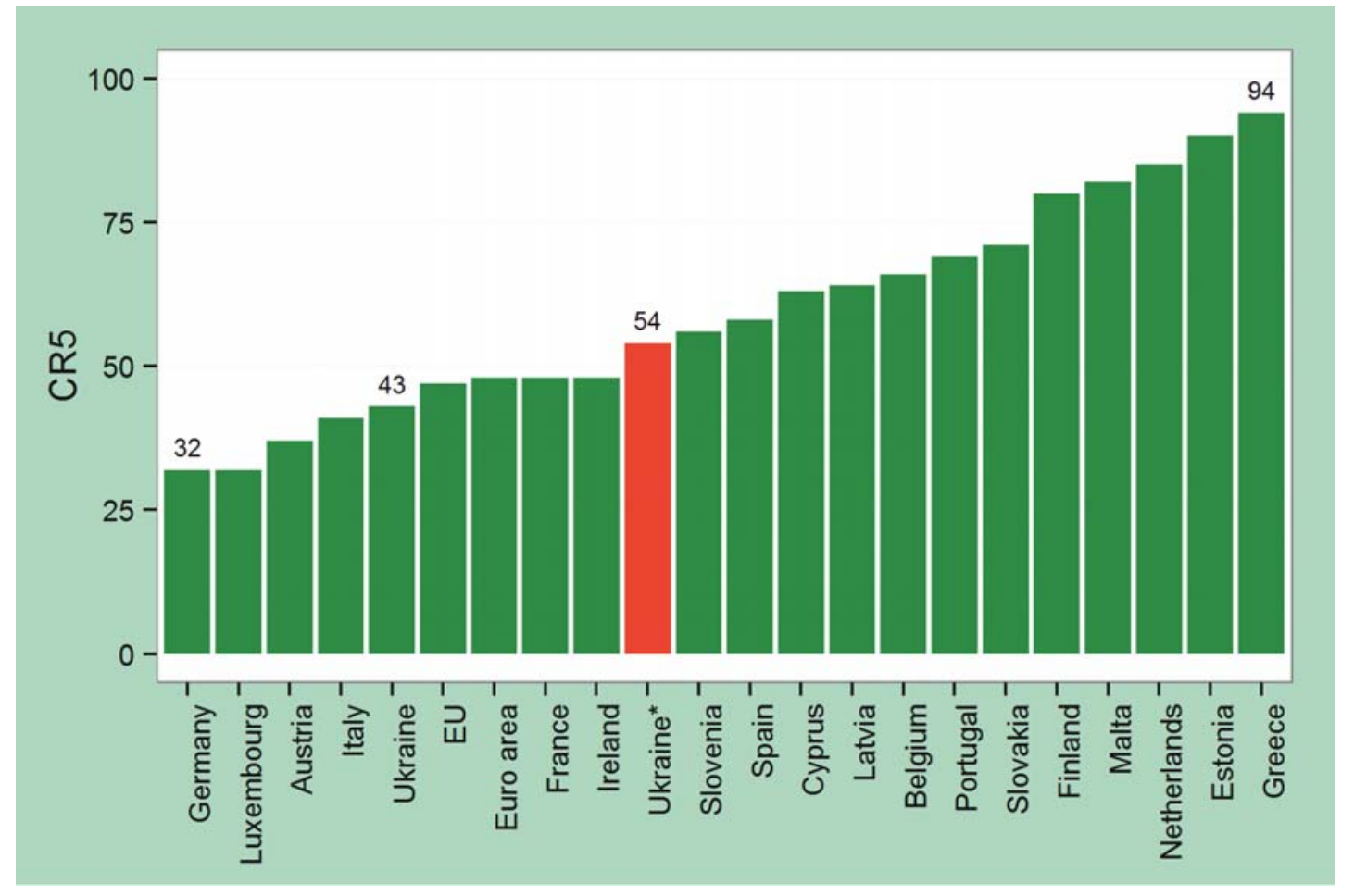

*- data for Ukraine as of 1 October 2015

As we can see, Ukraine's banking market is not as concentrated in asset terms as markets in many EU states, while already reaching the EU's average concentration level.

\section{d. What is the level of concentration of particular banking products markets?}

The first conclusion, which suggests an insignificant level of overall banking concentration in Ukraine is this: "so, there is no need whatsoever in any actions by the regulator for the time being?" A positive answer to this question would be somewhat premature in view of the differences in concentration levels of particular banking products markets. It is better to call this myth a generalization error, because experts often tend to assess the overall concentration of the banking market without breaking it down by products. Therefore, let's check the hypothesis claiming that concentration of markets for particular banking products in Ukraine still differs from the overall picture.

As we stated earlier in the methodological part of this study, objective analysis envisages additional study of concentration on particular product markets, because specialization and focusing make formation of even the so-called "segmented monopoly' in banking systems with low concentration theoretically possible.

According to our calculations, the market share of the largest Ukrainian bank differs substantially between its corporate and retail segments of the deposit and credit markets. This fact, and also differences in the total number of competitor banks in various segments, lead to substantial divergences in "product' concentration indicators. Let's illustrate the existing differences using $\mathrm{HHI}$ dynamics as an example for the individual bank deposit market. As Figure 12 shows, the overall concentration level of the retail deposit market is higher in comparison with indicators of the corporate deposit market. It can be explained by a substantial number of banks with corporate specialization. 
Figure 12. HHI dynamics on retail and corporate deposits market

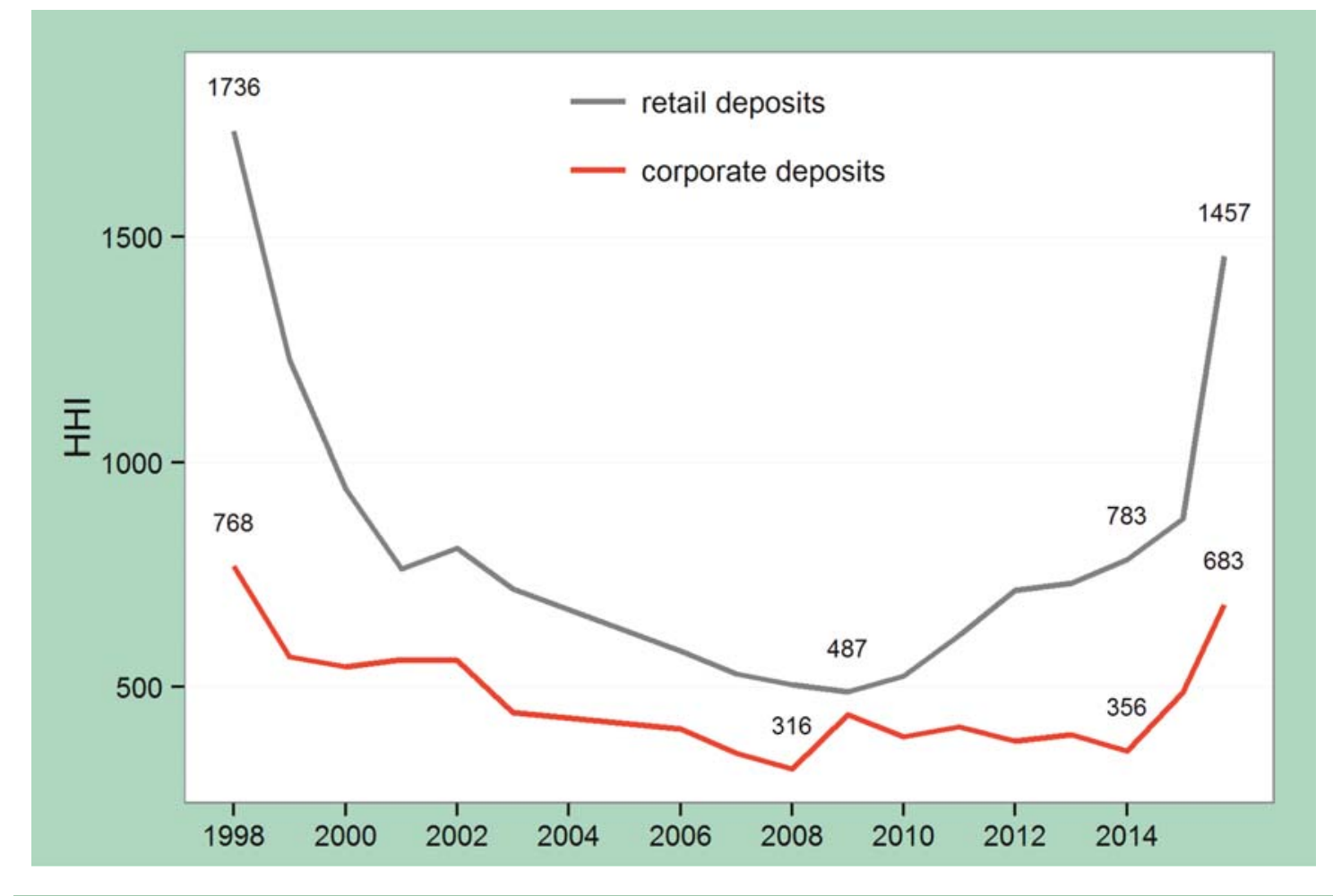

retail deposits; corporate deposits

The emergence of banks with retail business models during the formation of Ukraine's banking system and the loss of market-dominating positions by large post-Soviet financial institutions led to a sharp decline in the concentration of the individual deposit market in the late 1990s from 1,736 to 940 at the turn of the century. The concentration level continued to decline thereafter as well, but each year at a slower rate, reaching the minimum of 487 in the midst of the global financial crisis in 2009.

The introduction of over 90 temporary administrations in the wake of the 2008-2009 and 2014-2015 crises led to a sharp reduction of deposit product options on the market, while "cherry-picking" by certain banks, in view of the falling trust in most financial institutions, increased the inequality in the amount of deposits received by other existing banks. As a result, we observe the growth of the $\mathrm{HHI}$ for retail deposits market to 1,457 as of 1 October 2015 . The corresponding concentration indicator for corporate deposits market is half that amount: 683 (Table 3).

These trends in concentration dynamics in various segments of the deposit market are corroborated by $C R_{n}$ indexes, in particular, CR5 shown on Figure 13. The differences in concentration levels in various segments of the loan market are less significant than on the bank deposits market (Figure 14). A substantial decline in concentration of the retail loans market took place during 2006-2012 - hypothetically, as a result of the pre-crisis boom in auto and mortgage loans caused by the activity of European banks and the subsequent post-crisis increase of the shares of certain Ukrainian and Russian banks in the consumer micro-financing market.

The overall distribution of historical $H H I$ values for various products, shown on Figure 15, proves the higher concentration of the retail banking. During 2015, the $\mathrm{HHI}$ for individual deposits and loans entered the moderate concentration area according to EU standards, the corporate loans market is nearing the 1,000 mark, while the corporate deposits market remains at a low concentration (Table 3). Therefore, financial regulators conducting monitoring should pay greater attention to the banking retail market inclined to higher concentration than the market in general, while consolidation processes on the retail market will produce bigger changes in concentration.

We assume that further segmentation of the banking market by various product subcategories might show even more substantial differences in concentration, but such a detailed study cannot be done on the basis of publicly-available data. 
Figure 13. Dynamics of CR5 concentration indexes per assets and deposit market segments

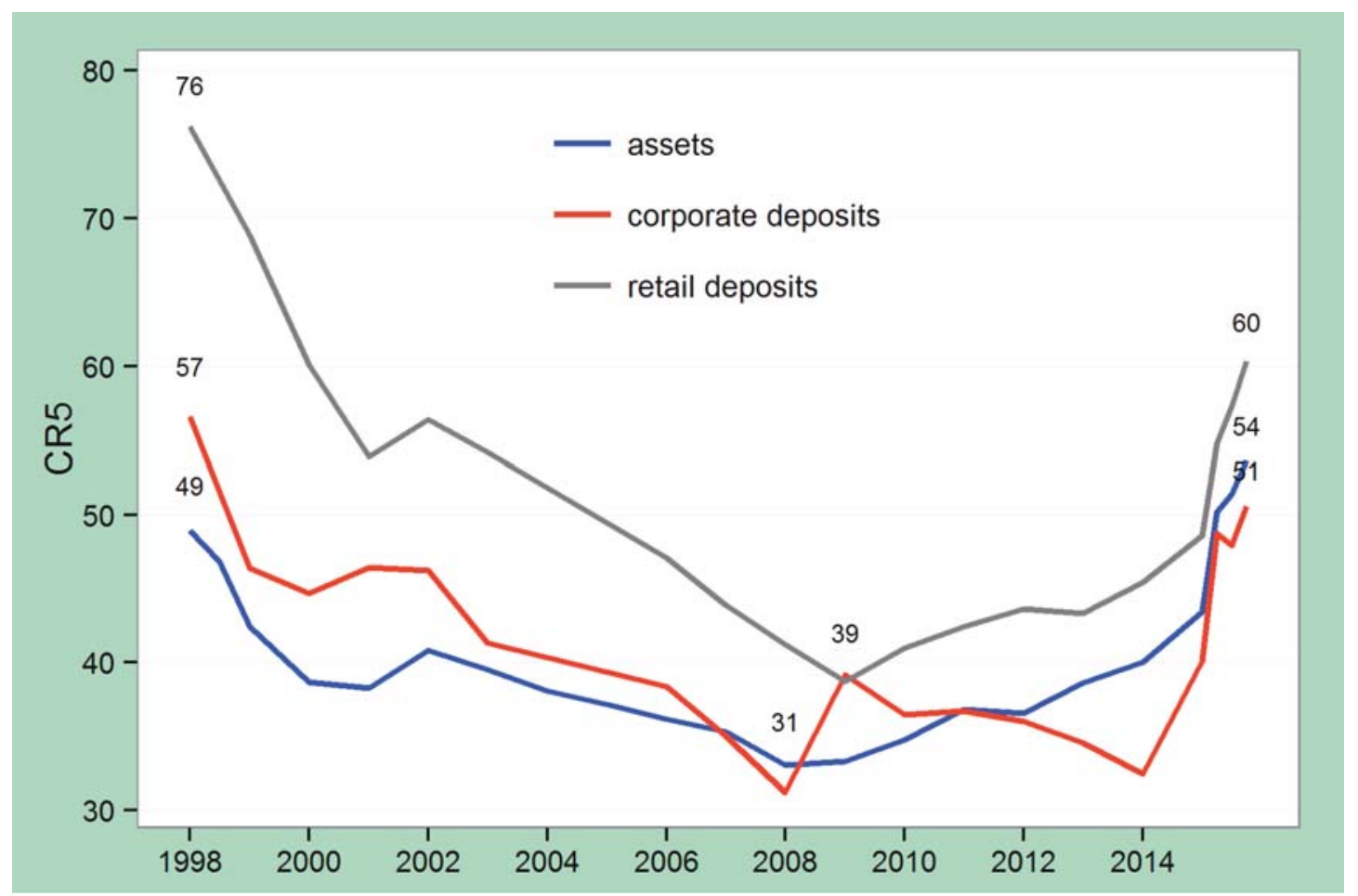

Figure 14. $\mathrm{HHI}$ dynamics on the retail and corporate loan market

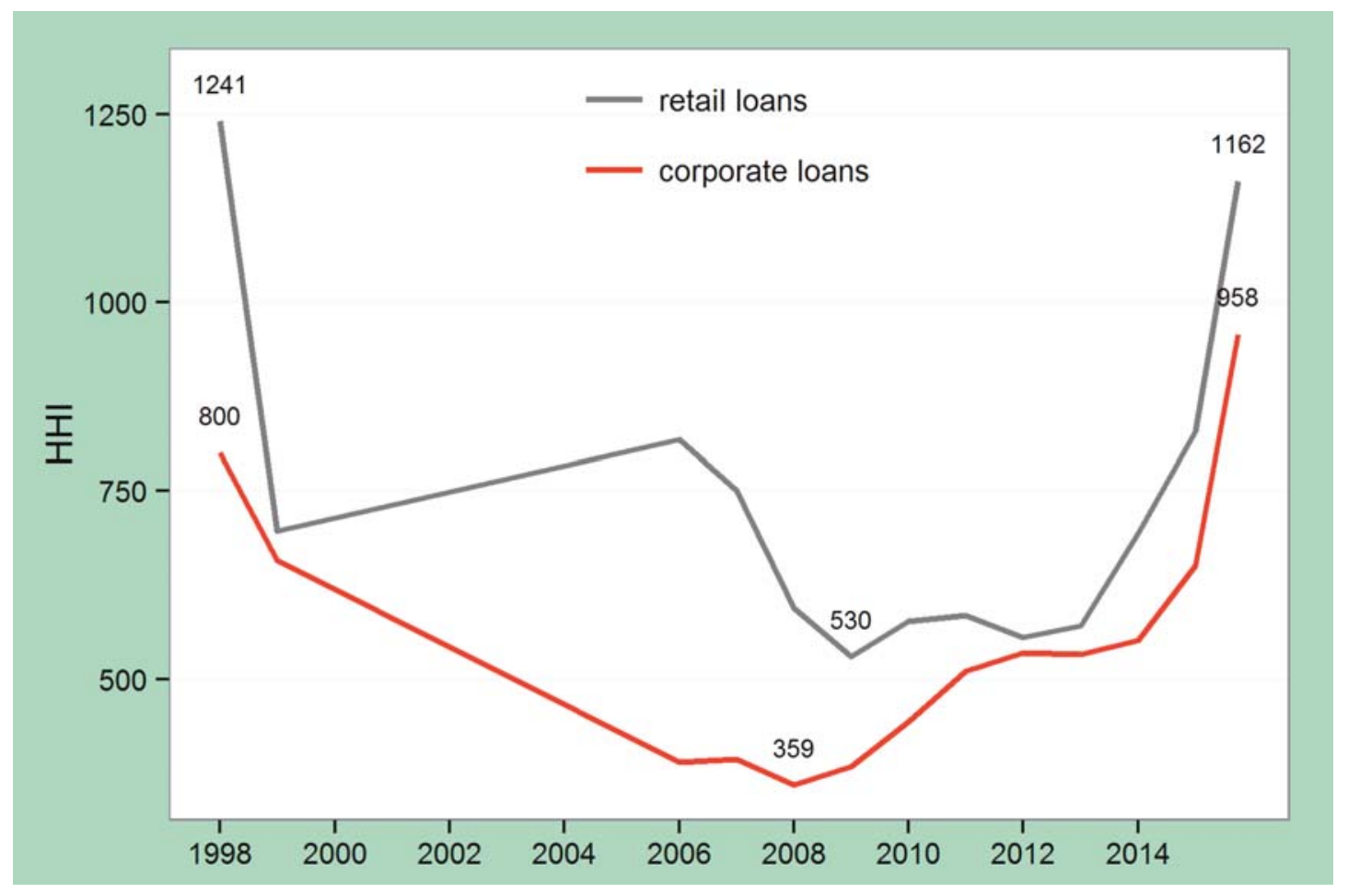

retail loans; corporate loans 


\section{Figure 15. Distribution of historical $H H I$ values on banking product} markets, 2005-2015

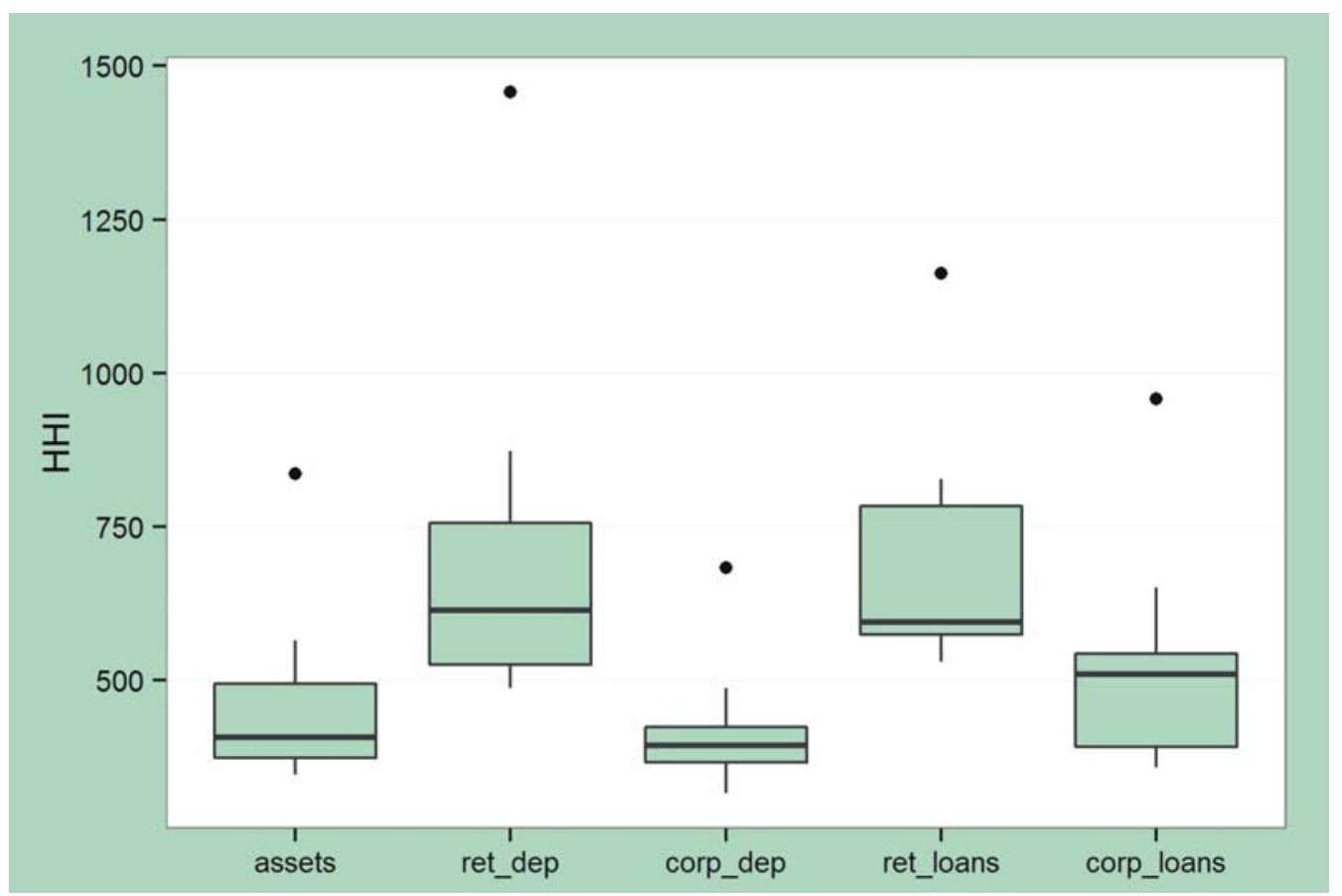

The same is true for the rest of markets for non-interest banking products. Considering the open data, we assume that there are signs of excessive concentration in certain segments of the bank payments market. For example, assuming that banks' market shares are distributed proportionally to the number of such nonfinancial indicators as active payment cards issued by these banks, operational ATMs, and other, we can obtain the following $H H I$ values: 3,062 (number of active payment cards), 3,372 (ATM network), and 4,163 (POS terminal network).

Therefore, before jumping to conclusions based on the general aggregated data for asset or capital concentration, or the total amount of loans or deposits without breaking them down by product types, it is worth paying attention to problems related to the limits of the banking services markets and structural particularities of inequality.

\section{e. How may the exit of banks affect concentration?}

Our retrospective analysis shows that the exit of banks from the market as a form of systemic consolidation was the key factor behind the growing concentration in recent years. Therefore, there are grounds for the myth that continuing cleansing of the banking system will produce a significant concentration increase in the future, even though its levels today are low or moderate. However, our hypothesis will state that the exit of small and medium banks would have an insignificant effect on the future level of concentration.

Within this context, let's tackle the practical problem of assessing the effect of a decline in the number of banks on the concentration level. Using the Monte Carlo method, we'll calculate the maximum and minimum increase of bank concentration indexes in Ukraine due to the continuing trend toward a reduction in the number of active banks after introduction of temporary administration.

Let's take the target number of banks after reduction as: $k=100$. First, we'll make a number of assumptions for a simulated model of banks exiting the market:

- There are two periods: before $(t)$ and after $(t+1)$ the exit of banks.

- Let $t=1$ October 2015, then the total number of solvent banks on the market is $n=123$. 
- The number of banks removed from the market in the future period: $n_{\text {def }}=n-k=123-100=23$.

- During the $(t+1)$ period, the market will lose assets of liquidated banks which will not be taken over by active financial institutions.

- The volume of assets of every active bank remains the same as of $t$ and as of $(t+1)$.

1) Let's assume that the probability of liquidation is the same for all banks in the system regardless of their size

By taking 10,000 random samples of banks containing k out of $\mathrm{n}$ banks operating during the t period each, we'll calculate 10,000 scenarios for future distribution of market shares in Ukraine's banking system. For every set of market shares showing possible future scenarios of market organization, we'll calculate potential concentration indicators. To determine the standard deviation of the study, we'll conduct several series of similar simulations.

The statistical characteristics of our calculation results regarding the range of possible $H H I$ and $C R 5$ values are shown in Table 4 and illustrated in Figure 16.

\section{Figure 16. Distribution of asset concentration indicators due to a decrease of the number of banks to 100 (simulation of 50,000 possible bank exit scenarios for the overall system)}

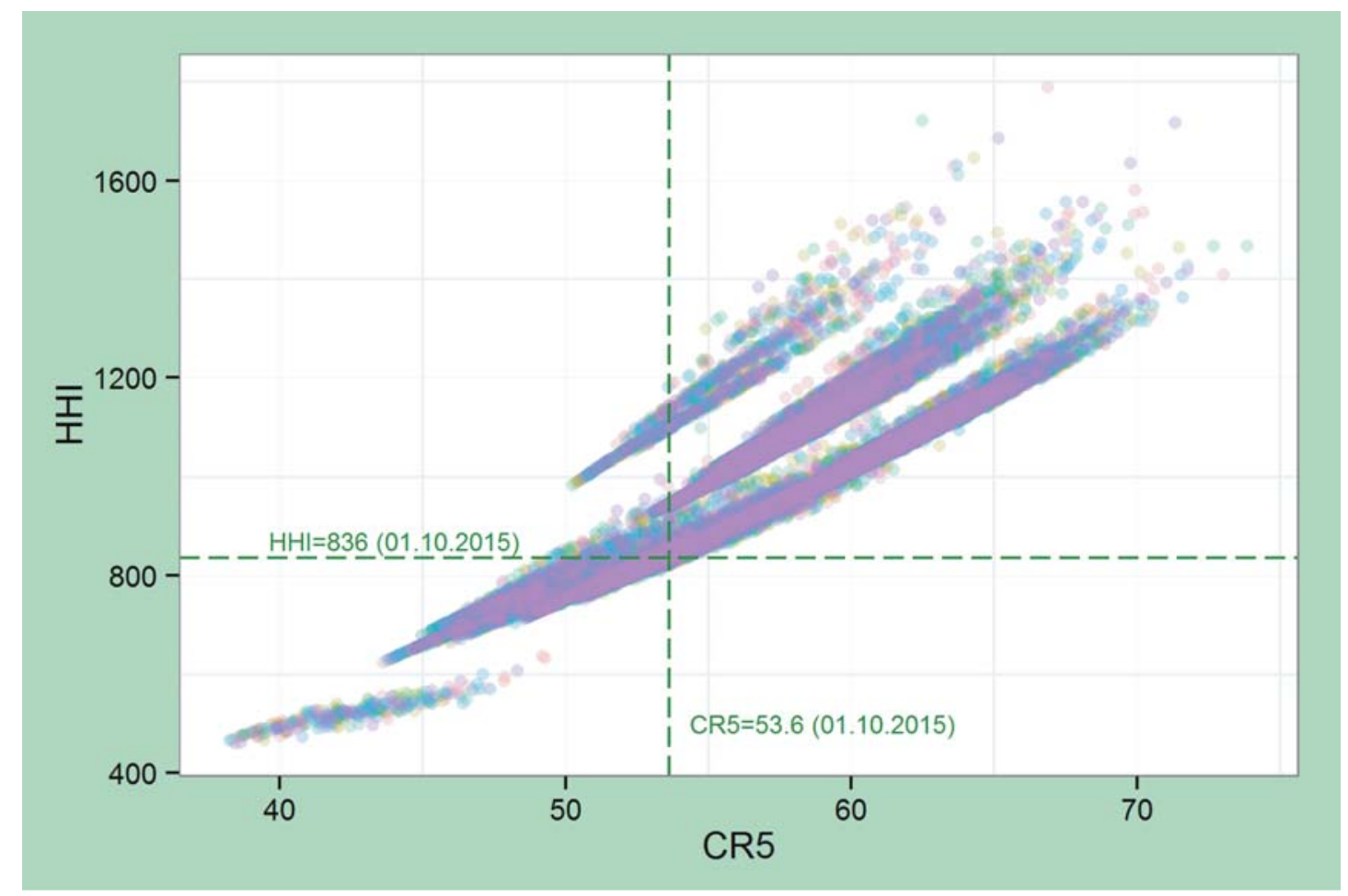

The results show that the maximum possible and very improbable $H H I$ values after reduction of the number of banks to 100 will be less than 1,800, not reaching the lower boundary of the high concentration area (given the invariable volume of assets and absence of mergers and acquisitions). On average, the HHI will grow to 1,007 and CR5 to 58\%. At the same time, there are possible yet hardly probable scenarios of declining concentration indexes to 458 and $38 \%$, respectively (Table 4).

It is worth noting that of the many hypothetical combinations we received, especially those involving simultaneous liquidation of many systemically-important banks with preservation of small ones, make no economic sense, and therefore, one has to take into account that the probability of a bank default is historically higher for small financial institutions. 
In that case, 10,000 random samples will be taken first among small banks (sub-sampling), so that, after adding them to the preserved banks of groups I to III, the total number of banks in the sampling is 100 . After that, we'll calculate market shares and concentration indicators using the same algorithm.

After a decrease in the number of banks to 100 due to the exit of small banks only, the $H H I$ will grow to 859 on average (which is not much higher than the initial indicator), with the maximum value not exceeding 873 and the minimum value approximately 847 . The $C R 5$ index will vary within the $54-55 \%$ range, and therefore, will remain virtually unchanged because the aggregate share of the five largest banks will increase by 1 percentage point at the most due to proportional growth of market shares. It would be fair to disregard the factor of exit of the smallest banks, for the unevenness in natural growth of market leaders has a much stronger influence over the future CR5 indicator.

\section{Figure 17. Statistical distribution of asset concentration indicators due to a decrease in the number of banks to 100 (simulation of 50,000 possible market exit scenarios for the group of the smallest banks)}

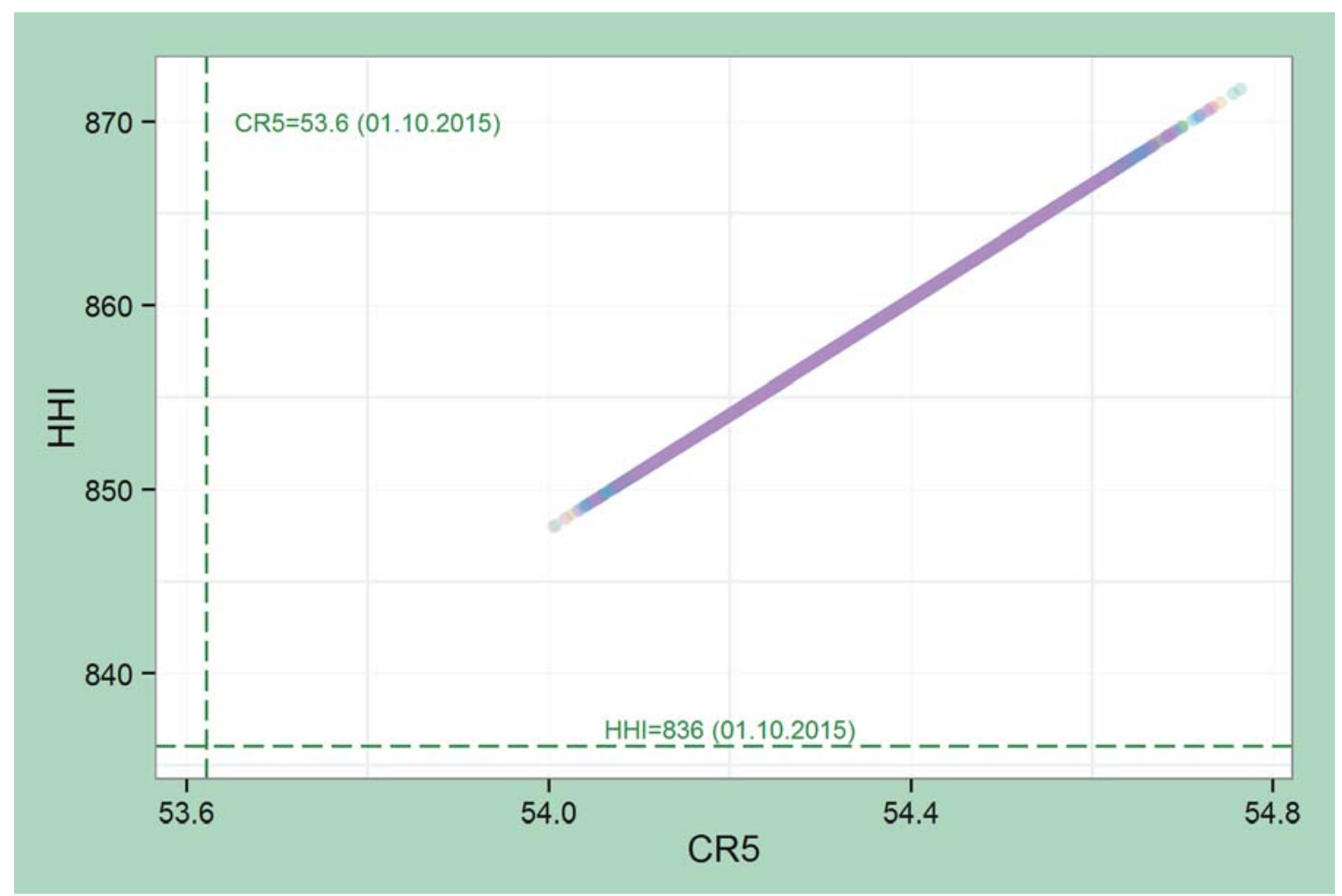

3) Let's assume that only the banks of groups 3 and 4 per NBU classification will exit the market, $k=50$.

Due to reduction of the number of banks to $k=50$ due to the exit of banks from groups III and IV only, the average $H H I$ will increase to 983 , which is only $18 \%$ higher than it was as of 1 October 2015 . In that case, the maximum $H H I$ will reach 1,016 and the minimum approximately 944 . CR5 concentration indexes will stay within the $57-60 \%$ range.

The results we obtained refute the myth regarding future monopolization and excessive concentration of assets on Ukraine's banking market solely due to a decline in the number of banks. Even if we assume the same probability of default for every bank in the system, the overall $\mathrm{HHI}$ cannot reach beyond 1,324 with a 99\% probability (Table 4). On the other hand, one should not forget about the higher concentration of the retail market, uneven natural growth of certain banks and the potential effect on concentration of another consolidation channel, bank mergers, and acquisitions. 


\section{Figure 18. Statistical distribution of asset concentration indicators due to a decrease in the number of banks to 50 (simulation of 50,000 possible market exit scenarios for banks from the groups III and IV)}

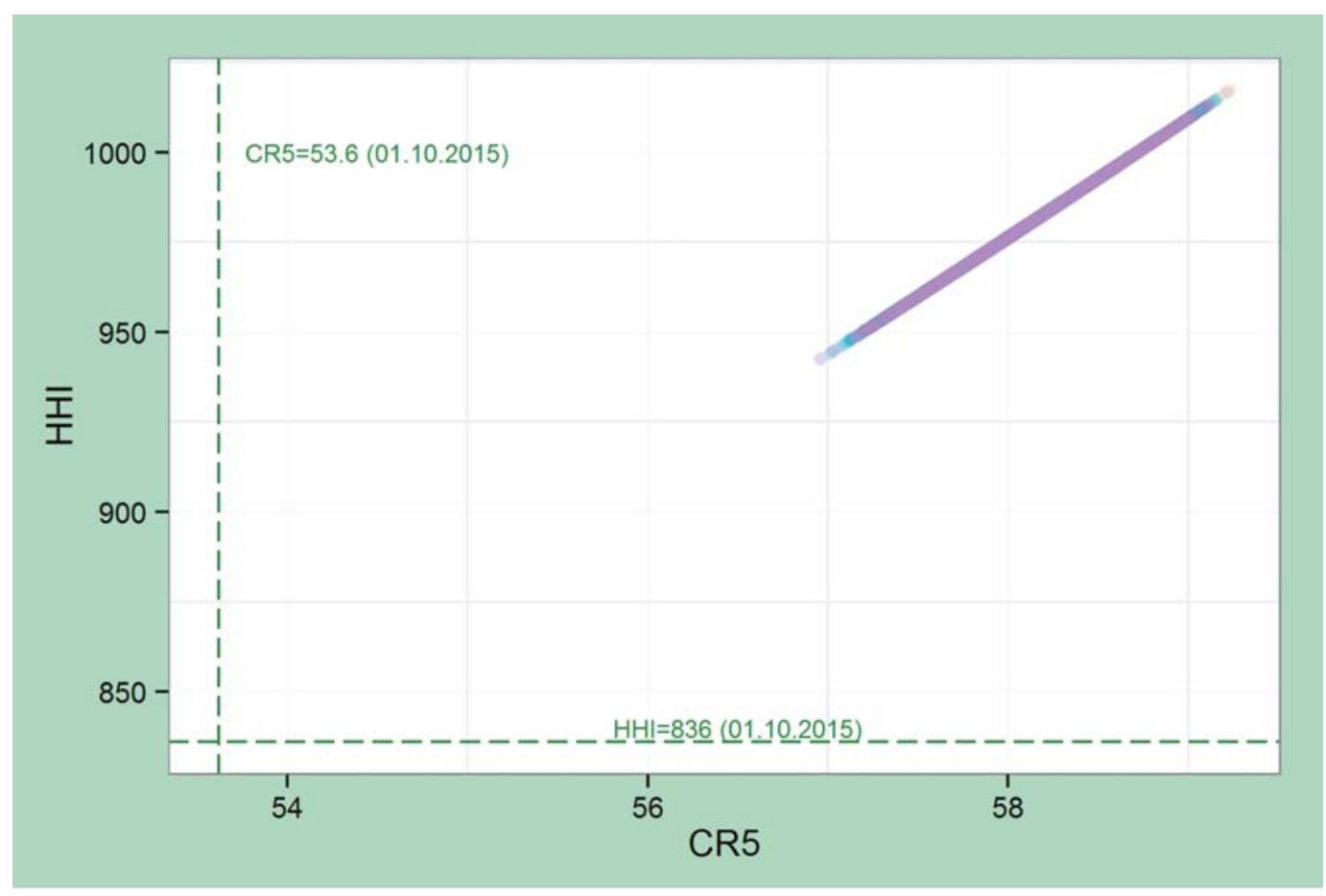

\section{f. Do regulators need to limit further mergers?}

The myth regarding the threat of increasing mergers and acquisitions that may intensify monopolization of the market has found a legislative reflection in the provisions envisaging a complex process of procuring mandatory permits from the AMCU and NBU for every merger. In order to dispel this myth, we'll check the hypothesis that mergers of small and medium banks will have an insignificant effect on market concentration, and therefore, there is no sense in limiting their reorganization under conditions of moderate concentration.

In Ukraine, consolidation of the banking market in the form of bank mergers may become an alternative to bankruptcy that will bring a positive effect on both the micro and macro levels. As a result of a merger, participating banks may achieve a number of individual goals on the way toward increased effectiveness and financial strength. According to the synergy theory, based on the assumption that managers acts in the interests of shareholders, a key motivation for a merger could be to obtain synergetic effects in the form of:

- operating synergy manifested in the savings on operating expenses, reduced operational ineffectiveness, savings on innovative development costs, effects from combining complementary products, and an increased size of bank's market niche;

- financial synergy, i.e., optimization of taxation, the possibility of buying a bank below its book value, diversification of income sources and risks, and decreases in capital costs.

A large number of empirical studies have supported the synergy theory, including Davidson et al. (2009), Mukherjee et al. (2004), and Ramaswamy (1997).

According to the agency theory of free cash flow, mergers and acquisitions using debt financing may not only create added value for shareholders, but also help solve the principal-agent conflict (Jensen, 1986). Unlike the two former theories, the hubris theory envisaging irrationality of managers' decisions regarding mergers or acquisitions (Roll, 1986) turned out to be the least empirically substantiated (Rudik and Semenkova, 2000). 
According to theoretical and empirical conclusions drawn in most of the aforementioned studies, the increase of the overall capitalization and adequacy of regulatory capital, better adherence to minimum regulatory capital norms, a decline in the number of defaults and certain savings on liquidation costs, and an increase in the banking system's overall effectiveness via quality replacement of management and transformation of banks' business models may become positive macro-effects from intensification of mergers and acquisitions among Ukrainian banks.

On the other hand, skeptics may retort that bank mergers and acquisitions will drive the growth of concentration given an increasing market share of financial institutions after reorganization. In that case, it is important to find out whether the increase in concentration will be so critical that it would outweigh the positive effects of a merger. Since the additional consolidation effect from a decline in the number of banks was discussed above, let's focus on calculation of the effect from the growth of market shares.

The increase in concentration expressed via $\mathrm{HHI}$ ( $\mathrm{HHI}$.delta) can be calculated regardless of the overall market concentration by doubling the sum of market shares of merged banks (EC, 2004). If $x$ is the market share of bank 1 and $z$ is the market share of bank 2 , the contribution of these banks to the $H H I$ before a merger is $\left(x^{2}+z^{2}\right)$ and after a merger $(x+z)^{2}$. Therefore:

HHI.delta $=(x+z)^{2}-\left(x^{2}+z^{2}\right)=x^{2}+2 x z+z^{2}-x^{2}-z^{2}=2 x z$.

As follows from the above formula, mergers involving large banks would have the biggest effect on $\mathrm{HHI}$ growth. Consolidation of the smallest banks on the market has no significance for concentration increase.

\section{Figure 19. Dependence of $H H I$ increase on the size of consolidation participants' market shares}

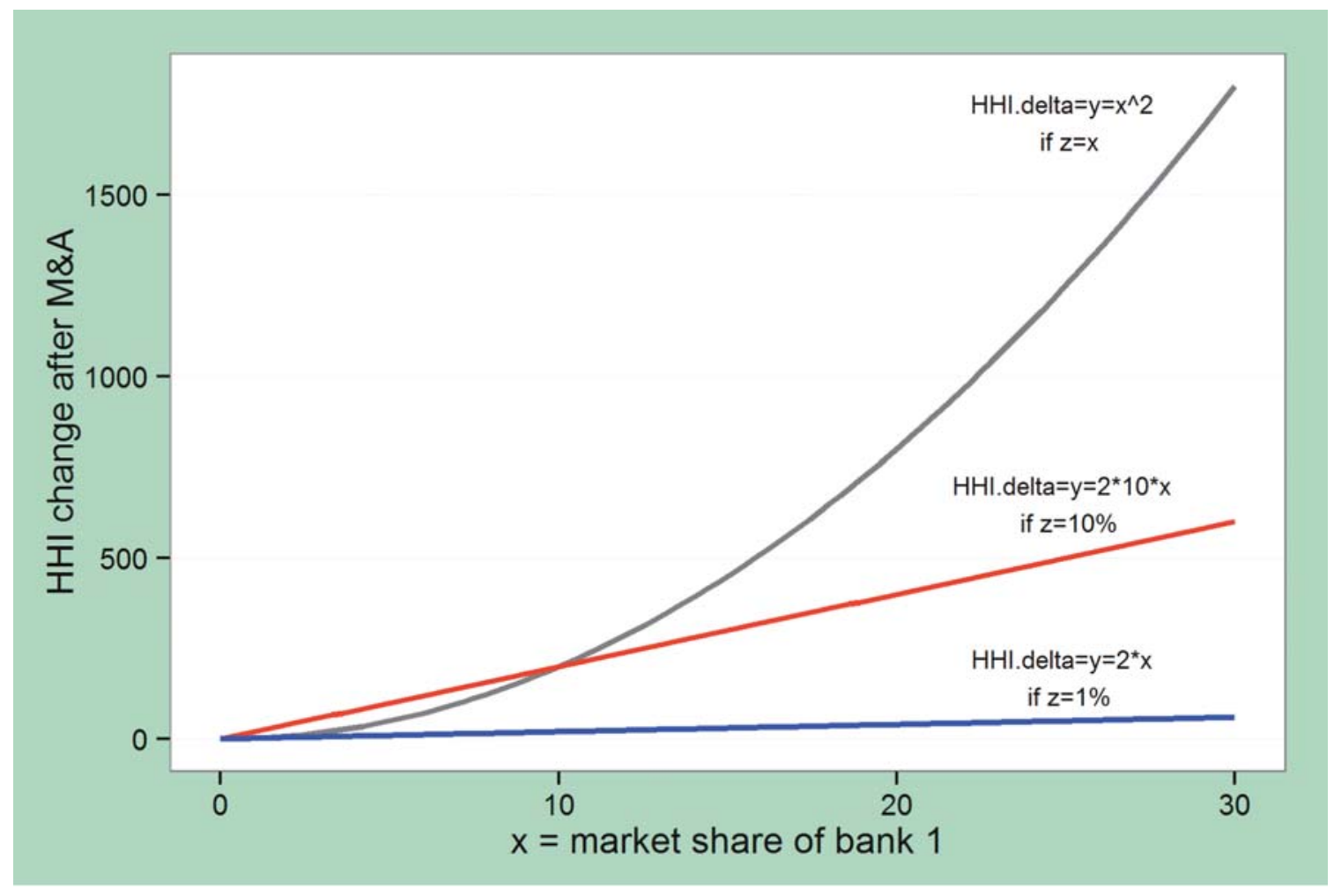

HHI increase after merger; $x=$ market share of bank 1 
If merging banks are identical in size, the $\mathrm{HHI}$ increase rate is nonlinearly intensifying as the market share of merging banks increases.

Let's calculate the $\mathrm{HHI}$ increase for Ukraine's banking system as a result of every possible merger or acquisition combination. For that purpose, we'll multiply the vector of solvent banks' market shares (in asset terms) as of 1 October 2015 (X) by the transposed identical vector $\left(\mathrm{X}^{\mathrm{t}}\right)$, and then multiply the resulting matrix by 2 . Then, we'll remove from the $\mathrm{HHI}$.delta entirety the matrix of all elements of its main diagonal that indicate the results of a merger between bank $x$ with bank $x$ that make no economic sense.

As follows from Figure 20 above, the number of M\&A agreement versions that could cause an $H H I$ increase over 100 is insignificant due to a substantial gap between the sizes of market shares of three market leaders. Most of the agreements will produce an increase below 50 points.

\section{Figure 20. The effect of hypothetical consolidation agreements on HHI increase (in asset terms) depending on the market share of an M\&A participant. Market shares as of 1 October 2015}

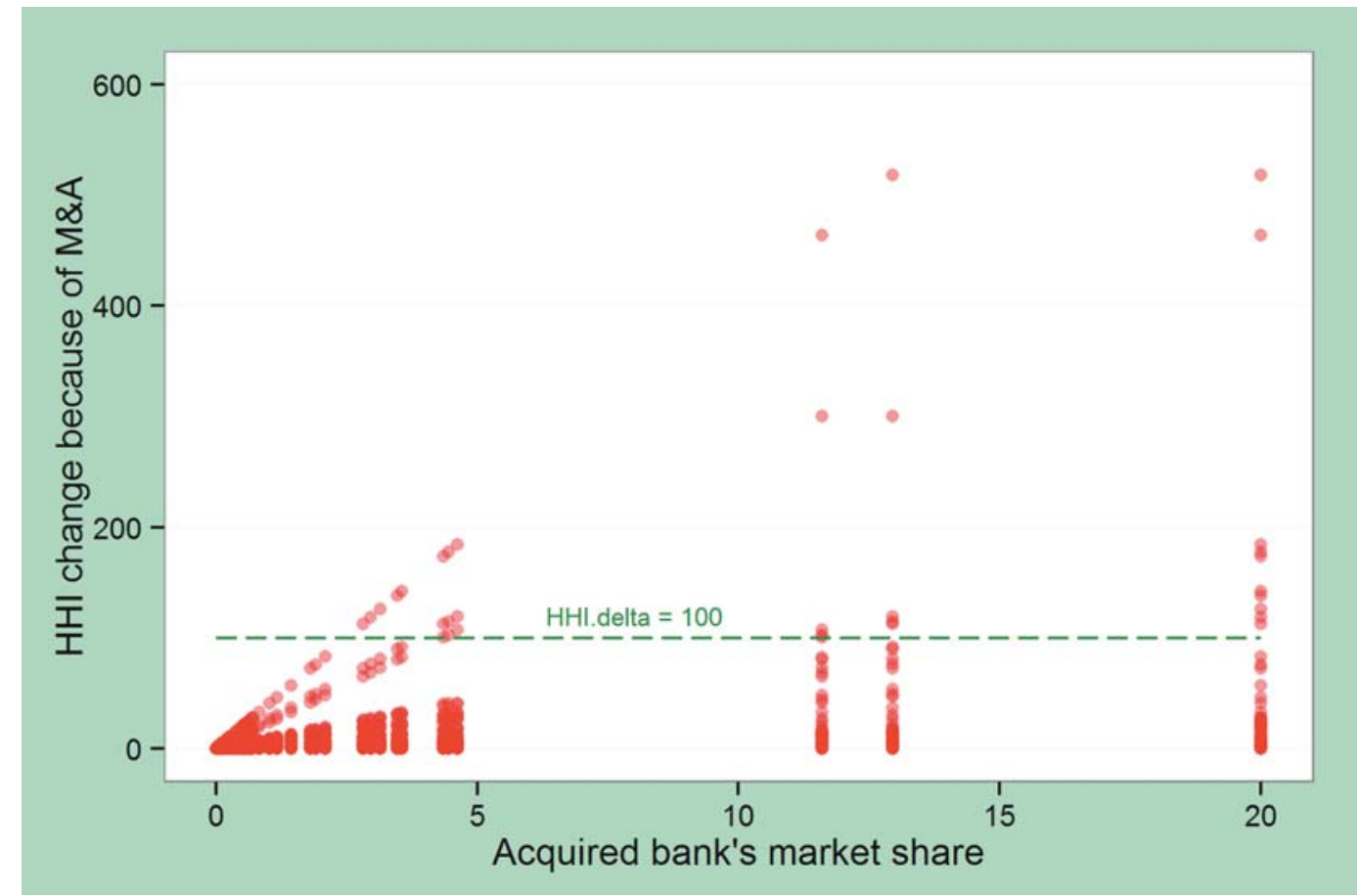

HHI increase due to an M\&A agreement; Market share of an M\&A participant bank, \%

Similar calculations for retail deposit markets produced similar results (Figure 21). The only difference was a bigger effect on the concentration of potential acquisitions involving the market's leader because of its market share of $34 \%$. Most Ukrainian banks (except the top 3) have a share of retail deposits market less than $5 \%$, which produce insignificant increases in concentration if these banks will be involved in mergers.

Even if we assumed that all banks from groups III and IV merged into a single bank with a market share of almost $10 \%$ and ranked $4^{\text {th }}$ in asset terms, concentration of the banking market will increase by only $105 \mathrm{HHI}$ points to the acceptable value of 941, whereas the CR5 would be less than $60 \%$.

Although we can draw a conclusion regarding the insignificant effect of small banks on concentration intuitively, based on the properties of concentration coefficients, our analysis allowed us to not only theoretically understand, but also quantitatively calculate, the level of this effect, which is especially important for calculation of the effect from not-so-unambiguous scenarios of banks' mergers with market leaders. 


\section{Figure 21. The effect of hypothetical consolidation agreements on the $\mathrm{HHI}$ increase (in retail deposit terms) depending on the market share of an M\&A participant. Market shares as of 1 October 2015}

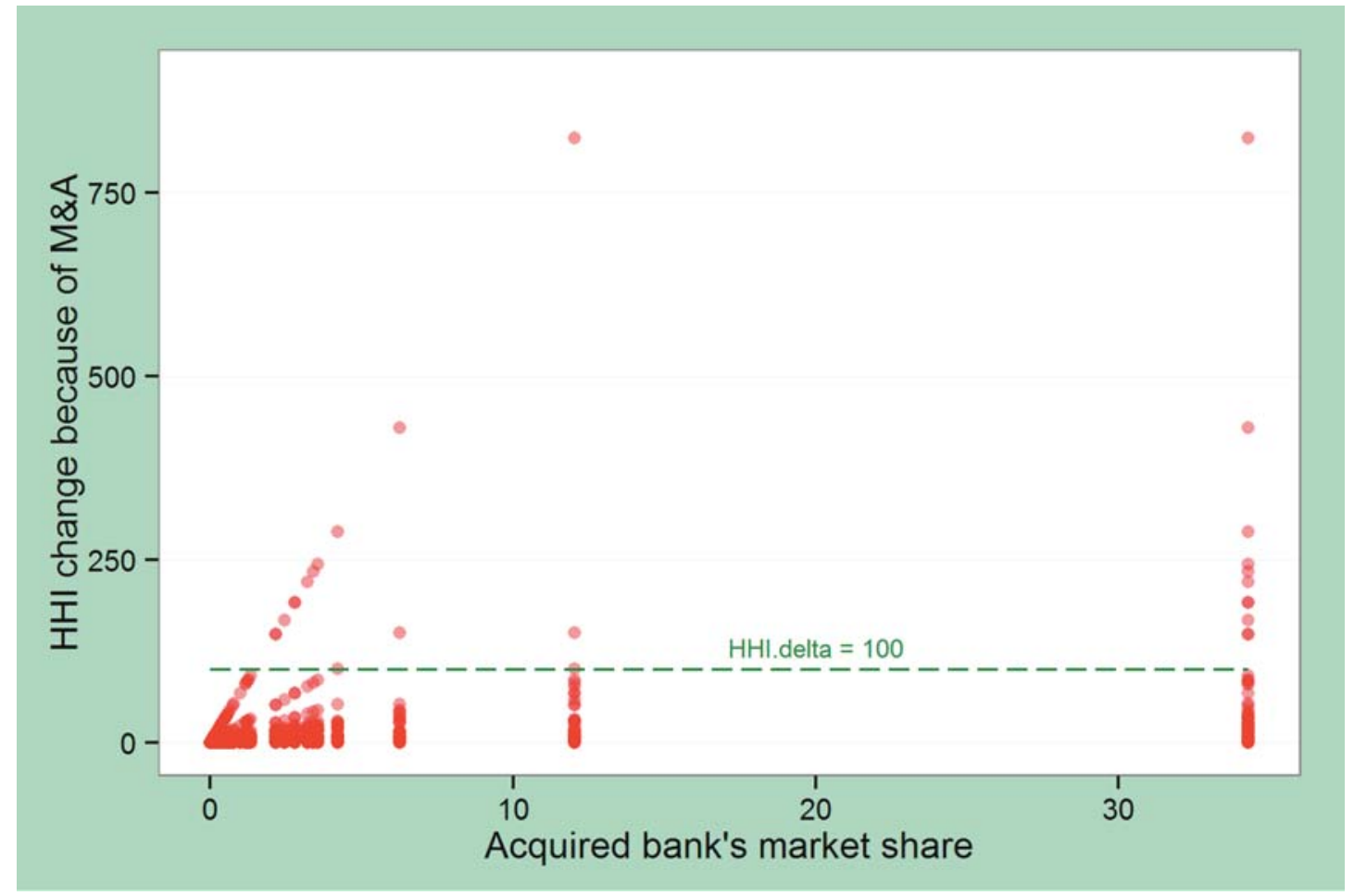

HHI increase due to an M\&A agreement; Market share of an M\&A participant bank, \%

Summing up the results of our empirical study, we were able to prove that mergers and acquisitions among banks of groups III and IV per NBU classification will not have a substantial effect on concentration growth. The effect will be limited even in the event of mass consolidation agreements combined with a decline in the number of banks. The history of mergers and acquisitions of Ukrainian banks additionally corroborates our conclusions regarding the absence of a direct effect from the mergers of small and medium banks on concentration growth (Table 5). Thus, despite the largest number of M\&A agreements during 1998-2003 (15 out of 25), this period witnessed a substantial decrease in concentration of Ukraine's banking system in view of decreasing inequality and growth of middle-echelon banks (including as a result of reorganization).

Strengthening of market positions of group I banks vis-à-vis the leader may become a bigger driver for concentration, increasing the number of merger and acquisition scenarios potentially important for the $\mathrm{HHI}$ (which is possible only if the largest banks are involved).

At this stage of the banking market's development, tightening requirements on capitalization and consolidation processes among small and medium banks do not pose an excessive concentration threat to the banking system from the viewpoint of best international practices and requirements of antimonopoly law. At the same time, considering the approach and transition of the banking system in terms of certain $\mathrm{HHI}$ indicators towards the moderate concentration area, it is prudent to develop a complex set of adequate preventive measures that accommodate the world's experience in regulation and oversight of systemically important banks whose involvement in consolidation processes has much higher consequences for financial strength and market organization.

\section{Recommendations for regulation policy}

In the course of development of preventive macroprudential instruments concerning concentration of the banking market, we recommend the following suggestions be taken into account: 
- $\quad$ The Herfindahl-Hirschman Index $(\mathbf{H H I})$ as the optimal indicator. It is advisable to select the regular HHI that comprehensively measures the level of concentration in the banking system as the target indicator to measure concentration. The AMCU should borrow from the NBU's experience in using $\mathrm{HHI}$ as the key concentration indicator. In turn, the NBU should, jointly with the AMCU, agree on the regulatory parameters for high, moderate, and low concentration limits and determine the corresponding minimum values for an $\mathrm{HHI}$ increase, below which a bank would have no sense applying for a merger permit.

All other indicators are supplementary. The CRn concentration indexes and inequality indicators should be used in the course of monitoring as supplementary informational indicators that better explain dynamics of particular concentration drivers, such as uneven natural growth of a group of large banks, a declining number of market participants, and dynamics of overall or bank group-specific inequality.

- Harmonization of Ukraine's antimonopoly legislation with EU's legislative framework. Considering the international experience in regulation of horizontal mergers, we recommend setting limits for concentration levels that would be uniform for all industries. At this stage, a separate calculation of national concentration norms for the banking market will not conform with the world practice of inter-industrial unification of requirements for regulation of horizontal mergers. Taking into account the course of reforms in Ukraine toward European integration, Ukrainian law should be adapted specifically to EU requirements. In particular, a free $M \& A$ regime without the need to apply for permits or go through complex approval procedures at the AMCU and NBU should be introduced for markets (including the main banking products markets) with low concentration $(H H K 1,000)$. M\&A agreements on these markets do not require additional in-depth analysis. For markets with moderate concentration $(1,000<H H K 2,000)$, an $\mathrm{HHI}$ increase by up to 250 points should not be viewed as threatening from the viewpoint of competition, and the limit for markets with excessive concentration $(H H I>2,000)$ should be set at 150 points in accordance with EC (2004). Exceptional situations not covered by an $\mathrm{HHI}$ increase should include: mergers of banks that are important innovators and whose market power cannot be measured by market share; cases of substantial cross-ownership of stocks in merger participants; when merger participants were involved in oligopolistic collusions in the past; etc. The $\mathrm{HHI}$ limits may be used as primary indicators of the absence of threats to competition. However, they should not be viewed at as a presumption of the existence or absence of threats.

- $\quad$ Continuous monitoring of concentration. Concentration of the banking system and dynamics of market organization in terms of key banking products should be regularly monitored to adjust the strictness of preventive antimonopoly measures depending on the concentration level. Monitoring of current concentration levels in comparison with historical dynamics is an indispensable condition for understanding the banking sector's development trends, and is widely used by the ECB and Federal Reserve System. In our case, monitoring provides a basis to determine how standard or extreme the present and future concentration indicators are from a retrospective viewpoint and given the pace of global changes. We suggest publishing banking concentration monitoring reports as thematic working papers and as part of the NBU's regular analytical reports in sections covering the structural dynamics of the banking market's development.

- $\quad$ Focusing on retail and payments market. At present, a monitoring system should be focused on the retail banking products market, especially the banking payments segment, considering both the relatively higher concentration and higher social significance of these products that determine public trust in the banking system's participants.

Focusing on market leaders. Regulatory authorities should concentrate their efforts on monitoring the natural growth rates and consolidation activities of the largest, including systemically important, banks. At the same time, attention should be devoted to heterogeneous organization of the group of banks with the largest market potential. Because of substantial differences in bank sizes, various tightening approaches should be used in macroprudential and antimonopoly monitoring of bank mergers depending on the market share of consolidation participants: from the maximal liberalization of agreements between small banks to restrictions on mergers of the largest banks, if detailed testing of the HHI's sensitivity will show that normative limits on particular banking products markets were exceeded.

- $\quad$ Free merger of microbanks. The requirements of antimonopoly and banking laws that prevent consolidation and capitalization of banks from groups III and IV per NBU classification should be loosened in view of the insignificant effect that reorganization of small banks has on the level of systemic risk and competition.

Cluster approach. When monitoring banking concentration, it is desirable to abandon a formalized approach to determination of market shares de-facto not independent financial institutions and pay closer attention to factors such as owners or related beneficiaries for certain bank groups, which increases the risk of collusion and strategic alliances among them. 
If we are to calculate the aggregate market shares for de facto related banks, we could obtain more accurate concentration indexes. In this context, bank clusters based on an ownership criterion must be additionally analyzed. Special attention should be devoted to the effect on the formation of market organization of certain clusters of public, foreign, and Ukrainian private banks that have common related parties.

\section{Concluding remarks}

The structure of Ukraine's banking market is far from ideal in view of the performance of its key function - efficient redistribution of credit resources. A low amount of equity in most banks, a large percentage of related party lending, a declining volume of deposit base due to the lowering public confidence in potentially insolvent banks - these are the problems that, if we are to overcome them, require, in particular, certain optimization of the banking market's structural characteristics.

The NBU's policy toward further consolidation and capitalization promotes transformation of the banking system by increasing the financial potential and reducing individual risks of Ukrainian banks. On the other hand, this process leads to the growing concentration of the banking sector, the consequences of which are debatable and attributed by many theoreticians to the threats of increasing monopolization and financial instability.

However, our empirical analysis proves that excessive concentration of Ukraine's banking market in 2016 is unlikely. At the same time, because of the differences in capitalization rates and continuing consolidation processes, the banking system may rise from a low to a moderate concentration level, which requires closer attention on the part of regulators to M\&A agreements involving systemically important banks, if they generate a high $\mathrm{HHI}$ increase. At the same time, concentration on the retail banking services (including payment) market requires closer monitoring, too.

The low effect of the inequality factor on concentration growth since the beginning of 2014 suggests the loosening of regulatory requirements on the reorganization of small and medium banks. Since the factor of the declining number of banks became the most essential for concentration, a decreasing number of defaults in the post-crisis period will help slow down the concentration rate. Moreover, even mass defaults or mergers of small banks will have an insignificant effect on the increase of concentration indexes, something that cannot be said about systemically important banks whose consolidation can generate structural changes on a much greater scale.

We consider the following as prospective areas of further studies: 1) detailed empirical assessments of the effect of concentration on the structure, effectiveness and systemic risk of Ukraine's banking market; 2) using the cluster approach for calculation of concentration on the basis of affinity of related parties; and 3) analysis of key motives and consequences of mergers of Ukrainian banks using historical financial data.

A precise assessment of the effect of capitalization, consolidation, and concentration processes on the dynamics of the banking market's organization will help implement a complex set of antimonopoly and macroprudential measures to help formation of a banking market with an optimal combination of financial effectiveness and systemic risk indicators.

\section{References}

- Admati A., Hellwig M. (2013). The bankers' new clothes: What's wrong with banking and what to do about It. Princeton University Press, Princeton, NJ.

- Allen F., Gale D. (2004). Competition and financial stability. Journal of Money, Credit and Banking, No. 36, pp. 453-480. https://doi.org/10.1353/mcb.2004.0038

- Amable B., Chatelain J.-B., De Bandt O. (2002). Optimal capacity in the banking sector and economic growth. Journal of Banking \& Finance, Vol. 26, No. 2-3, pp. 491-517. https://doi.org/10.1016/S0378-4266(01)00231-X

- Atkinson A., Micklewright J. (1992). Economic transformation in Eastern Europe and the distribution of income. Cambridge, Cambridge University Press. 
- Beck T., Demirgüç-Kunt A., Levine R. (2007). Bank Concentration and Fragility: Impact and Mechanics. NBER Chapters, in: The Risks of Financial Institutions, National Bureau of Economic Research, Inc., pp.193-234. https://doi.org/10.7208/chicago/9780226092980.003.0006

- Davidson I., Frank R., Ismail A. (2009). Operating performance of European bank mergers. Service Industries Journal, Vol. 29, No. 3, pp. 345-366.

- De Nicolo G., Lucchetta M. (2009). Financial intermediation, competition, and risk: A general equilibrium exposition. Working Paper, No. 105, IMF, Washington D.C. https://doi.org/10.5089/9781451872521.001

- ECB (2015). Report on financial structures. ECB, Frankfurt am Main.

- English W.B. (2002). Financial Consolidation and Monetary Policy. Economic Policy Review, Federal Reserve Bank of New York. Available at: https://www.newyorkfed.org/medialibrary/media/research/epr/02v08n1/0205engl.pdf

- EU (2004). Guidelines on the assessment of horizontal mergers under the Council Regulation on the control of concentrations between undertakings. Official Journal of the European Union, No. C 31, pp. 5-18.

- Fiordelisi F. (2009). Mergers and Acquisitions in European Banking. Palgrave Macmillan, UK. https://doi.org/10.1057/9780230245402

- Florian L. (2014). Measuring competition in banking: A critical review of methods. Serie Etudes et documents du CERDI, Etudes et Documents, No. 12.

- Group of Ten (2001). Consolidation in the Financial Sector, BIS.

- Haldane A.G. (2012). On being the right size. Annual Series, No. 22, Institute of Directors, London.

- Hall M., Tideman N. (1967). Measures of Concentration, Journal of the American Statistical Association, Vol. 62, pp. 162-168. https://doi.org/10.1080/01621459.1967.10482897

- Hay D.A. (1991). Industrial Economics and Organization: Theory and Evidence. Oxford University Press, Oxford.

- Hirschman A.O. (1964). The paternity of an index, American Economic Review, Vol. 54, No. 5, pp. 761-762.

- ljtsma P., Spierdijk L. (2015). Clarifying the Concentration-stability Controversy in Banking: Evidence from the EU-25.

- Jacquemin A. (1975). Une mesure entropique de la diversification des Enterprise. Revue Économique, Vol. 66, pp. 834-838.

- Jensen M.C. (1986). Agency Cost Of Free Cash Flow, Corporate Finance, and Takeovers. American Economic Review, Vol. 76, No. 2, pp. 323-329.

- Kalashnykov Gh.O. (2007). Slyjanye y poghloshhenye kompanyj po pravu Evropejskogho Sojuza, Mezhdunarodnye otnoshenyja, Moskva.

- Korecjka N.I. (2014). Proces koncentraciji rynku bankivsjkykh poslugh Ukrajiny: ocinka ta strateghiji pozycionuvannja, Ekonomichnyj forum.

- Koutsomanoli-Fillipaki N., Staikouras K.Ch. (2006). Competition and concentration in the New European banking Landscape. European Financial Management, European Financial Management Association, Vol. 12, No. 3, pp. 443-482.

- Laeven L., Ratnovski L., Tong H. (2014). Bank Size and Systemic Risk. Stuff Discussion Note, No. 14-04, IMF, pp. $1-33$.

- Liikanen E. (2012). Final Report of the High-level Expert Group on Reforming the Structure of the EU Banking Sector. Brussels. 
- Mester L.J. (2005). Optimal industrial structure in banking. Working Papers, No. 08-2, Federal Reserve Bank of Philadelphia. https://doi.org/10.2139/ssrn.1092217

- Mukherjee T.K., Kiymaz H., Baker H.K. (2004). Merger Motives and Target Valuation: A Survey of Evidence from CFOs. Journal of Applied Finance, Vol. 14, No. 2, pp. 7-24.

- NBU (2015). Comprehensive Program of Ukraine Financial Sector Development until 2020. NBU Board Resolution, No. 391.

- Pawłowska M. (2015). Changes in the size and structure of the European Union banking sector -the role of competition between banks. Working Paper, No. 205, NBP, pp. 4-37.

- Pohl M., Tortella T., Van der Wee H.(2001). A Century of Banking Consolidation in Europe: The History and Archives of Mergers and Acquisitions. Ashgate Publishing Limited, Aldershot, UK.

- Prozorov J. (2003). Koncentracija bankivsjkoji systemy Ukrajiny: podaljshi perspektyvy. Visnyk of the National Bank of Ukraine, No. 1, pp. 54-56.

- Ramaswamy K. (1997). The Performance Impact Of Strategic Similarity In Horizontal Mergers: Evidence From The U.S. Banking Industry. Academy of Management Journal, Vol. 40, No. 3, pp. 697-715.

- Ratti R.A., Lee S., Seol Y. (2008). Bank concentration and financial constraints on firm-level investment in Europe. Journal of Banking and Finance, No. 32, pp. 2684-2694. https://doi.org/10.1016/j.jbankfin.2008.07.001

- Roll R. (1986). The Hubris Hypothesis of Corporate Takeovers. Journal of Business, Vol. 59, Issue 2, pp. $197-216$. https://doi.org/10.1086/296325

- Rudyk N., Semenkova Y. (2000). Rynok korporativnogo kontrolya: sliyaniya, zhestkie pogloshcheniya i vykupy dolgovym finansirovaniem, Finansy i statistika, $456 \mathrm{p}$.

- Santomero A.M., Seater J.J. (2000). Is there an optimal size for the financial sector? Journal of Banking \& Finance, Vol. 24, No. 6, pp. 945-965.

- Stephan A., Tsapin A., Talavera O. (2012). Main Bank Power, Switching Costs, and Firm Performance: Theory and Evidence from Ukraine. Emerging Markets Finance and Trade, Vol. 48, No. 2, pp. $76-93$. https://doi.org/10.2753/REE1540-496X480205

- Tirole J. (1988). The Theory of Industrial Organization. MIT Press, Cambridge.

- U.S. Department of Justice and the Federal Trade Commission (1992). Horizontal Merger Guidelines, Issued: April 2, 1992.

- U.S. Department of Justice and the Federal Trade Commission (2010). Horizontal Merger Guidelines, Issued: August 19, 2010.

- Uhde A., Heimeshoff U. (2009). Consolidation in banking and financial stability in Europe: Empirical evidence. Journal of Banking \& Finance, No. 33, pp. 1299-1311. https://doi.org/10.1016/j.jbankfin.2009.01.006

- Van Hoose D. (2010). The Industrial Organization of Banking, Bank Behavior, Market Structure, and Regulation. Springer-Verlag, Berlin Heidelberg.

- Vickers J. (2012). Some economics of banking reform. University of Oxford, Department of Economics, Discussion Paper Series, No. 632.

- World Bank (2013). Rethinking the Role of the State in Finance. Global Financial Development Report 2013, Washington D.C. 


\section{Annexes}

\section{Table 1. Dynamics of asset concentration in Ukraine's banking system from 1 January 1998 to 1 October 2015}

\begin{tabular}{|c|c|c|c|c|c|c|c|c|c|c|c|c|c|}
\hline Date & CR3 & CR4 & CR5 & CR10 & CR25 & CR50 & HHI & Gini & RS & $\begin{array}{l}\text { Atkin- } \\
\text { son }\end{array}$ & Theil & $\begin{array}{c}\text { Variation } \\
\text { coef. }\end{array}$ & GE \\
\hline 01.01 .1998 & 35.0 & 42.0 & 48.9 & 68.8 & 82.1 & 90.6 & 639.2 & 0.83 & 0.69 & 0.59 & 1.73 & 3.27 & 1.45 \\
\hline 01.01.1999 & 29.8 & 36.7 & 42.4 & 60.8 & 78.1 & 88.0 & 486.0 & 0.78 & 0.64 & 0.52 & 1.43 & 2.74 & 1.23 \\
\hline 01.01 .2000 & 25.6 & 32.9 & 38.6 & 57.0 & 73.6 & 85.8 & 409.9 & 0.74 & 0.59 & 0.46 & 1.22 & 2.41 & 1.06 \\
\hline 01.01 .2001 & 26.3 & 32.5 & 38.3 & 55.8 & 71.9 & 84.2 & 400.6 & 0.71 & 0.56 & 0.42 & 1.11 & 2.28 & 0.95 \\
\hline 01.01 .2002 & 28.8 & 35.1 & 40.8 & 55.1 & 71.3 & 84.3 & 425.4 & 0.70 & 0.55 & 0.42 & 1.11 & 2.34 & 0.94 \\
\hline 01.01 .2003 & 27.5 & 34.3 & 39.5 & 54.2 & 71.3 & 84.4 & 407.4 & 0.71 & 0.55 & 0.42 & 1.12 & 2.31 & 0.96 \\
\hline 01.01 .2004 & 27.3 & 32.9 & 38.1 & 53.7 & 71.7 & 85.3 & 394.5 & 0.72 & 0.56 & 0.43 & 1.12 & 2.28 & 0.99 \\
\hline 01.01 .2005 & 27.7 & 32.9 & 37.2 & 53.1 & 72.0 & 85.7 & 394.4 & 0.72 & 0.57 & 0.44 & 1.13 & 2.30 & 1.00 \\
\hline 01.01.2006 & 26.1 & 31.2 & 36.2 & 53.8 & 73.5 & 87.0 & 389.4 & 0.74 & 0.60 & 0.46 & 1.18 & 2.31 & 1.06 \\
\hline 01.01.2007 & 24.7 & 30.2 & 35.3 & 52.4 & 74.3 & 87.7 & 372.8 & 0.75 & 0.61 & 0.47 & 1.21 & 2.30 & 1.09 \\
\hline 01.01 .2008 & 23.1 & 28.3 & 33.1 & 49.7 & 75.2 & 88.2 & 346.2 & 0.76 & 0.62 & 0.49 & 1.21 & 2.23 & 1.13 \\
\hline 01.01.2009 & 22.0 & 28.0 & 33.3 & 52.0 & 76.4 & 89.3 & 354.0 & 0.78 & 0.64 & 0.52 & 1.30 & 2.33 & 1.22 \\
\hline 01.01.2010 & 23.3 & 29.5 & 34.8 & 53.2 & 77.1 & 90.0 & 375.0 & 0.79 & 0.65 & 0.53 & 1.33 & 2.39 & 1.25 \\
\hline 01.01 .2011 & 26.1 & 31.9 & 36.8 & 53.9 & 75.9 & 88.6 & 407.3 & 0.77 & 0.63 & 0.51 & 1.30 & 2.48 & 1.19 \\
\hline 01.01 .2012 & 27.9 & 32.8 & 36.6 & 52.8 & 74.6 & 87.1 & 426.5 & 0.76 & 0.61 & 0.49 & 1.28 & 2.54 & 1.15 \\
\hline 01.01 .2013 & 30.7 & 35.0 & 38.6 & 52.7 & 74.7 & 87.0 & 470.6 & 0.76 & 0.61 & 0.50 & 1.31 & 2.69 & 1.16 \\
\hline 01.01 .2014 & 32.3 & 36.6 & 40.0 & 54.3 & 76.0 & 87.5 & 517.4 & 0.78 & 0.63 & 0.51 & 1.39 & 2.88 & 1.21 \\
\hline 01.01 .2015 & 34.8 & 39.4 & 43.4 & 59.7 & 82.0 & 92.0 & 564.5 & 0.80 & 0.66 & 0.56 & 1.48 & 2.81 & 1.33 \\
\hline $01.04 .2015 *$ & 40.9 & 45.8 & 50.2 & 67.5 & 86.6 & 94.7 & 729.5 & 0.82 & 0.68 & 0.58 & 1.58 & 2.95 & 1.42 \\
\hline $01.07 .2015 *$ & 42.6 & 47.2 & 51.4 & 68.7 & 87.8 & 95.6 & 778.9 & 0.83 & 0.69 & 0.59 & 1.60 & 2.98 & 1.45 \\
\hline 01.10 .2015 & 44.6 & 49.2 & 53.6 & 71.1 & 88.7 & 96.1 & 836.0 & 0.83 & 0.70 & 0.60 & 1.64 & 3.05 & 1.48 \\
\hline $\begin{array}{l}\text { Number of } \\
\text { values }\end{array}$ & 19 & 19 & 19 & 19 & 19 & 19 & 19 & 19 & 19 & 19 & 19 & 19 & 19 \\
\hline $\begin{array}{l}\text { Period's } \\
\text { average }\end{array}$ & 28.6 & 34.3 & 39.2 & 56.0 & 75.8 & 87.8 & 453.5 & 0.76 & 0.61 & 0.49 & 1.30 & 2.52 & 1.15 \\
\hline $\begin{array}{l}\text { Standard } \\
\text { divergence }\end{array}$ & 5.3 & 5.1 & 5.1 & 5.6 & 4.4 & 2.9 & 118.8 & 0.04 & 0.04 & 0.06 & 0.18 & 0.30 & 0.16 \\
\hline Median & 27.5 & 32.9 & 38.3 & 53.9 & 74.7 & 87.5 & 407.4 & 0.76 & 0.61 & 0.49 & 1.28 & 2.39 & 1.15 \\
\hline Minimum & 22.0 & 28.0 & 33.1 & 49.7 & 71.3 & 84.2 & 346.2 & 0.70 & 0.55 & 0.42 & 1.11 & 2.23 & 0.94 \\
\hline Maximum & 44.6 & 49.2 & 53.6 & 71.1 & 88.7 & 96.1 & 836.0 & 0.83 & 0.70 & 0.60 & 1.73 & 3.27 & 1.48 \\
\hline Asymmetry & 1.4 & 1.3 & 1.3 & 1.6 & 1.3 & 1.0 & 1.9 & 0.18 & 0.16 & 0.39 & 0.97 & 1.05 & 0.49 \\
\hline Excess & 1.9 & 1.6 & 1.3 & 1.5 & 1.3 & 0.9 & 3.1 & -1.00 & -1.00 & -0.83 & 0.04 & -0.13 & -0.71 \\
\hline $\begin{array}{l}\text { Standard } \\
\text { error }\end{array}$ & 1.2 & 1.2 & 1.2 & 1.3 & 1.0 & 0.7 & 27.3 & 0.01 & 0.01 & 0.01 & 0.04 & 0.07 & 0.04 \\
\hline
\end{tabular}

*data for 1Q and 2Q 2015 are for reference purposes only and were not included in calculation of descriptive statistics Source: NBU, authors' calculations 


\section{Table 2. Factor analysis of asset concentration increase from 1}

\section{January 2014 to 1 October 2015}

\begin{tabular}{|c|c|c|c|c|c|c|}
\hline Indicator & $\begin{array}{c}1 \text { January } 2014 \\
\text { (market's actual) }\end{array}$ & $\begin{array}{c}1 \text { January } 2014 \\
\text { (hypothetically for } \\
\text { banks that avoided } \\
\text { default) }\end{array}$ & $\begin{array}{l}1 \text { October } 2015 \\
\text { (market's actual) }\end{array}$ & $\begin{array}{c}\text { Effect from decline } \\
\text { in the number of } \\
\text { banks, } \%\end{array}$ & $\begin{array}{l}\text { Effect from internal } \\
\text { structural changes in } \\
\text { the subgroup of healthy } \\
\text { banks, } \%\end{array}$ & $\begin{array}{c}\text { Total effect } \\
\text { on indicator's } \\
\text { increase, \% }\end{array}$ \\
\hline CR4 & 36.61 & 47.31 & 49.18 & 85.17 & 14.83 & 100 \\
\hline CR5 & 40.01 & 51.78 & 53.62 & 86.48 & 13.52 & 100 \\
\hline CR10 & 54.28 & 68.66 & 71.12 & 85.38 & 14.62 & 100 \\
\hline CR25 & 76.02 & 86.03 & 88.67 & 79.15 & 20.85 & 100 \\
\hline $\mathrm{HHI}$ & 517.38 & 835.70 & 836.03 & 99.90 & 0.10 & 100 \\
\hline Gini & 0.78 & 0.81 & 0.83 & 57.09 & 42.91 & 100 \\
\hline RS & 0.63 & 0.67 & 0.70 & 56.45 & 43.55 & 100 \\
\hline Atkinson & 0.51 & 0.56 & 0.60 & 55.04 & 44.96 & 100 \\
\hline Theil & 1.39 & 1.54 & 1.64 & 58.97 & 41.03 & 100 \\
\hline sd & 1.61 & 2.51 & 2.49 & 102.03 & -2.03 & 100 \\
\hline var.coeff & 2.88 & 3.02 & 3.05 & 82.75 & 17.25 & 100 \\
\hline entropy & 1.21 & 1.35 & 1.48 & 53.80 & 46.20 & 100 \\
\hline
\end{tabular}

Source: NBU, authors' calculations

\section{Table 3. Concentration of banking services markets in Ukraine} as of 1 October 2015

\begin{tabular}{|l|}
\hline $\begin{array}{c}\text { Concentration / inequality } \\
\text { indicator }\end{array}$ \\
\hline CR3 \\
\hline CR4 \\
\hline CR5 \\
\hline CR10 \\
\hline CR25 \\
\hline CR50 \\
\hline HHI \\
\hline Gini \\
\hline RS \\
\hline Atkinson \\
\hline Theil \\
\hline Variation \\
\hline GE \\
\hline
\end{tabular}

\begin{tabular}{|c|}
\hline $\begin{array}{c}\text { Banking market (in } \\
\text { asset terms) }\end{array}$ \\
\hline 44.6 \\
\hline 49.2 \\
\hline 53.6 \\
\hline 71.1 \\
\hline 88.7 \\
\hline 96.1 \\
\hline 836.0 \\
\hline 0.83 \\
\hline 0.70 \\
\hline 0.60 \\
\hline 1.64 \\
\hline 3.05 \\
\hline
\end{tabular}

\begin{tabular}{|c|}
\hline $\begin{array}{c}\text { Retail } \\
\text { deposits }\end{array}$ \\
\hline 52.6 \\
\hline 56.8 \\
\hline 60.3 \\
\hline 75.0 \\
\hline 90.8 \\
\hline 97.7 \\
\hline 1457.1 \\
\hline 0.87 \\
\hline 0.72 \\
\hline 0.69 \\
\hline 1.93 \\
\hline 4.11 \\
\hline 1.76 \\
\hline
\end{tabular}

\begin{tabular}{|c|}
\hline $\begin{array}{c}\text { Corporate } \\
\text { deposits }\end{array}$ \\
\hline 39.2 \\
\hline 45.3 \\
\hline 50.6 \\
\hline 67.7 \\
\hline 88.7 \\
\hline 97.0 \\
\hline 683.3 \\
\hline 0.83 \\
\hline 0.69 \\
\hline 0.61 \\
\hline 1.55 \\
\hline 2.72 \\
\hline 1.51 \\
\hline
\end{tabular}

\begin{tabular}{|c|}
\hline Retail loans \\
\hline 49.5 \\
\hline 57.4 \\
\hline 63.7 \\
\hline 79.5 \\
\hline 95.0 \\
\hline 99.1 \\
\hline 1161.9 \\
\hline 0.89 \\
\hline 0.76 \\
\hline 0.74 \\
\hline 1.96 \\
\hline 3.65 \\
\hline 1.95 \\
\hline
\end{tabular}

\begin{tabular}{|c|}
\hline Corporate loans \\
\hline 43.8 \\
\hline 51.0 \\
\hline 57.6 \\
\hline 72.6 \\
\hline 89.9 \\
\hline 96.4 \\
\hline 957.6 \\
\hline 0.84 \\
\hline 0.71 \\
\hline 0.63 \\
\hline 1.71 \\
\hline 3.28 \\
\hline 1.57 \\
\hline
\end{tabular}

Source: NBU, authors' calculations 
Table 4. Simulated forecast of concentration levels of Ukraine's banking system due to banks' exit from the market, under the condition of a declining number of financial institutions in 2016 *

\begin{tabular}{|c|c|c|c|c|c|c|c|c|c|c|c|c|}
\hline \multicolumn{13}{|c|}{ All banks under exit risk, $k=100$} \\
\hline $\begin{array}{l}\text { Simulation } \\
\text { set }\end{array}$ & mean.hhi & sd.hhi & $\min . h h i$ & median.hhi & q.099.hhi & max.hhi & mean.cr5 & sd.cr5 & $\min . c r 5$ & $\begin{array}{l}\text { median. } \\
\text { cr5 }\end{array}$ & q.099.cr5 & $\max . \mathrm{cr} 5$ \\
\hline 1 & 1008.61 & 132.81 & 463.46 & 1012.80 & 1321.32 & 1653.67 & 57.99 & 4.08 & 38.64 & 58.42 & 66.07 & 71.21 \\
\hline 2 & 1007.28 & 130.64 & 476.65 & 1011.55 & 1328.77 & 1596.42 & 57.96 & 4.06 & 38.76 & 58.35 & 66.17 & 71.10 \\
\hline 3 & 1006.53 & 133.14 & 458.29 & 1011.89 & 1324.86 & 1743.05 & 57.91 & 4.11 & 38.68 & 58.30 & 66.33 & 71.86 \\
\hline 4 & 1007.02 & 131.42 & 472.37 & 1012.49 & 1321.01 & 1613.26 & 57.94 & 4.10 & 38.67 & 58.37 & 66.22 & 71.24 \\
\hline 5 & 1007.44 & 129.97 & 477.43 & 1011.62 & 1324.76 & 1634.22 & 57.99 & 4.01 & 39.26 & 58.35 & 66.22 & 71.32 \\
\hline mean & 1007.38 & 131.60 & 469.64 & 1012.07 & 1324.15 & 1648.12 & 57.96 & 4.07 & 38.80 & 58.36 & 66.20 & 71.35 \\
\hline sd & 0.77 & 1.36 & 8.43 & 0.55 & 3.16 & 57.28 & 0.03 & 0.04 & 0.26 & 0.04 & 0.10 & 0.30 \\
\hline \multicolumn{13}{|c|}{ Small banks under exit risk, k=100 } \\
\hline $\begin{array}{l}\text { Simulation } \\
\text { set }\end{array}$ & mean.hhi & sd.hhi & $\min$. hhi & median.hhi & q.099.hhi & max.hhi & mean.cr5 & sd.cr5 & $\min . c r 5$ & $\begin{array}{l}\text { median. } \\
\text { cr5 }\end{array}$ & q.099.cr5 & $\max . c r 5$ \\
\hline 1 & 858.76 & 3.18 & 847.95 & 858.71 & 866.19 & 872.49 & 54.35 & 0.10 & 54.00 & 54.35 & 54.59 & 54.79 \\
\hline 2 & 858.71 & 3.15 & 849.21 & 858.61 & 866.25 & 871.23 & 54.35 & 0.10 & 54.04 & 54.35 & 54.59 & 54.75 \\
\hline 3 & 858.70 & 3.15 & 848.80 & 858.64 & 866.23 & 870.90 & 54.35 & 0.10 & 54.03 & 54.35 & 54.59 & 54.74 \\
\hline 4 & 858.74 & 3.16 & 848.43 & 858.65 & 866.37 & 870.16 & 54.35 & 0.10 & 54.02 & 54.35 & 54.59 & 54.71 \\
\hline 5 & 858.73 & 3.16 & 848.48 & 858.67 & 866.19 & 871.28 & 54.35 & 0.10 & 54.02 & 54.35 & 54.59 & 54.75 \\
\hline mean & 858.73 & 3.16 & 848.57 & 858.65 & 866.25 & 871.21 & 54.35 & 0.10 & 54.02 & 54.35 & 54.59 & 54.75 \\
\hline sd & 0.02 & 0.01 & 0.47 & 0.04 & 0.07 & 0.84 & 0.00 & 0.00 & 0.01 & 0.00 & 0.00 & 0.03 \\
\hline \multicolumn{13}{|c|}{ Small and medium banks under exit risk, $k=50$} \\
\hline $\begin{array}{l}\text { Simulation } \\
\text { set }\end{array}$ & mean.hhi & sd.hhi & $\min$. hhi & median.hhi & q.099.hhi & max.hhi & mean.cr5 & sd.cr5 & $\min . c r 5$ & $\begin{array}{l}\text { median. } \\
\text { cr5 }\end{array}$ & q.099.cr5 & $\max . c r 5$ \\
\hline 1 & 983.13 & 10.10 & 947.41 & 983.43 & 1004.32 & 1013.51 & 58.21 & 0.31 & 57.11 & 58.22 & 58.85 & 59.12 \\
\hline 2 & 983.27 & 9.98 & 944.32 & 983.67 & 1004.54 & 1014.78 & 58.22 & 0.30 & 57.02 & 58.23 & 58.86 & 59.16 \\
\hline 3 & 983.34 & 10.06 & 944.12 & 983.61 & 1004.35 & 1013.28 & 58.22 & 0.31 & 57.02 & 58.23 & 58.85 & 59.12 \\
\hline 4 & 983.25 & 10.06 & 947.58 & 983.52 & 1004.72 & 1015.99 & 58.21 & 0.31 & 57.12 & 58.22 & 58.86 & 59.20 \\
\hline 5 & 983.43 & 9.99 & 950.22 & 983.62 & 1005.11 & 1013.82 & 58.22 & 0.30 & 57.20 & 58.23 & 58.87 & 59.13 \\
\hline mean & 983.28 & 10.04 & 946.73 & 983.57 & 1004.61 & 1014.28 & 58.22 & 0.30 & 57.10 & 58.23 & 58.86 & 59.14 \\
\hline sd & 0.11 & 0.05 & 2.55 & 0.10 & 0.32 & 1.11 & 0.00 & 0.00 & 0.08 & 0.00 & 0.01 & 0.03 \\
\hline
\end{tabular}

*Five sets of Monte Carlo simulations ( 1 set $=10,000$ scenarios of bank exits and corresponding changes in concentration indexes).

Legend:

$K$ - total number of banks on the market after exit

Mean - mean value of HHI or CR4

$S d$-standard divergence
Min - minimum value

Median - value distribution median

q.0.99-0.99 distribution quantile

Max-maximum value 


\section{Table 5. Mergers and acquisitions of Ukrainian banks from}

\section{8 to 2015}

\begin{tabular}{|c|c|c|c|c|c|}
\hline No & Acquiring bank & City & Target bank & City & $\begin{array}{l}\text { Merger / ac- } \\
\text { quisition year }\end{array}$ \\
\hline 1 & Mriya (present-day VTB Bank) & Kyiv & Ros & Bila Tserkva & 1998 \\
\hline 2 & Zorya & Rivne & Paritet & Donetsk & 1998 \\
\hline 3 & Aval (present-day Raiffeisen Bank Aval) & Kyiv & Ternopil Credit & Ternopil & 1998 \\
\hline 4 & Ukrgazbank & Kyiv & Service & Shostka & 1998 \\
\hline 5 & Avtokrazbank & Poltava & Ukruniversalbank & Bila Tserkva & 1999 \\
\hline 6 & Stolychnyi & Kyiv & Armand & Odesa & 1999 \\
\hline 7 & Nadra & Kyiv & Slobozhanshchyna & Sumy & 2000 \\
\hline 8 & Nadra & Kyiv & Kyivo-Pecherskyi & Kyiv & 2000 \\
\hline 9 & Ukoopspilka & Kyiv & Podillia & Khmelnytskyi & 2000 \\
\hline 10 & Ukrgazbank & Kyiv & Ukrnaftogazbank & Kyiv & 2000 \\
\hline 11 & Investbank & Odesa & Arkadia & Odesa & 2000 \\
\hline 12 & $\begin{array}{l}\text { International Commercial Bank (present-day } \\
\text { Piraeus Bank MKB) }\end{array}$ & Kyiv & Tavria & Theodosia & 2001 \\
\hline 13 & Ukrgazbank & Kyiv & People's Bank & Kyiv & 2002 \\
\hline 14 & Aval (present-day Raiffeisen Bank Aval) & Kyiv & Etalon & Kyiv & 2002 \\
\hline 15 & $\begin{array}{l}\text { Ukrainian Bank for Trade Cooperation (later } \\
\text { Inprombank) }\end{array}$ & Kharkiv & $\begin{array}{l}\text { Innovative-Industrial } \\
\text { Bank }\end{array}$ & Kyiv & 2003 \\
\hline 16 & Industrial Bank & Zaporizhia & MT Bank & Kremenchuk & 2005 \\
\hline 17 & $\begin{array}{l}\text { United Commercial Bank (later European Bank } \\
\text { for Development and Savings) }\end{array}$ & Simferopol & $\begin{array}{l}\text { European Bank for De- } \\
\text { velopment and Savings }\end{array}$ & Kyiv & 2006 \\
\hline 18 & Unikreditbank & Lutsk & HVB Bank Ukraine & Kyiv & 2007 \\
\hline 19 & VTB Bank (Mriya) & Kyiv & Vneshtorgbank & Kyiv & 2007 \\
\hline 20 & SEB Bank (present-day Fidobank) & Kyiv & Factorial Bank & Kharkiv & 2009 \\
\hline 21 & Swedbank (later Omega Bank) & Kyiv & Swedbank Invest & Kyiv & 2009 \\
\hline 22 & PUMB & Kyiv & Dongorbank & Donetsk & 2011 \\
\hline 23 & Bank Credit Agricole & Kyiv & CIB Credit Agricole & Kyiv & 2012 \\
\hline 24 & Fidobank & Kyiv & Fidokombank & Kyiv & 2013 \\
\hline 25 & Ukrsotsbank (Unicredit Bank) & Kyiv & Unikreditbank & Kyiv & 2013 \\
\hline
\end{tabular}

